\title{
Graphene oxide and electroactive reduced graphene oxide- based composite fibrous scaffolds for engineering excitable nerve tissue
}

DOI:

10.1016/j.msec.2020.111632

\section{Document Version}

Accepted author manuscript

Link to publication record in Manchester Research Explorer

Citation for published version (APA):

Magaz, A., Li, X., Gough, J., \& Blaker, J. (2020). Graphene oxide and electroactive reduced graphene oxide-based composite fibrous scaffolds for engineering excitable nerve tissue. Materials Science and Engineering C: Materials for Biological Applications . https://doi.org/10.1016/j.msec.2020.111632

Published in:

Materials Science and Engineering C: Materials for Biological Applications

\section{Citing this paper}

Please note that where the full-text provided on Manchester Research Explorer is the Author Accepted Manuscript or Proof version this may differ from the final Published version. If citing, it is advised that you check and use the publisher's definitive version.

\section{General rights}

Copyright and moral rights for the publications made accessible in the Research Explorer are retained by the authors and/or other copyright owners and it is a condition of accessing publications that users recognise and abide by the legal requirements associated with these rights.

\section{Takedown policy}

If you believe that this document breaches copyright please refer to the University of Manchester's Takedown Procedures [http://man.ac.uk/04Y6Bo] or contact uml.scholarlycommunications@manchester.ac.uk providing relevant details, so we can investigate your claim.

\section{OPEN ACCESS}




\section{Graphene oxide and electroactive reduced graphene oxide-based}

2 composite fibrous scaffolds for engineering excitable nerve tissue

3 Adrián Magaz ${ }^{\mathrm{ab}}, \mathrm{Xu} \mathrm{Li}^{\mathrm{bc}}$, Julie E. Gough ${ }^{\mathrm{a}}$, Jonny J. Blaker ${ }^{\mathrm{ad} *}$

4 a Department of Materials and Henry Royce Institute, The University of Manchester, 5 Manchester, M13 9PL, United Kingdom

6 b Institute of Materials Research and Engineering (IMRE), Agency for Science Technology and 7 Research (A*STAR), 138634, Singapore

$8 \quad$ cDepartment of Chemistry, National University of Singapore, 117543, Singapore

9 department of Biomaterials, Institute of Clinical Dentistry, University of Oslo, Oslo, 0317, 10 Norway

$11 *$ *Corresponding author, email: jonny.blaker@manchester.ac.uk

12 Abstract

13 This study systematically investigates the role of graphene oxide (GO) and reduced GO/silk14 based composite micro/nano- fibrous scaffolds in regulating neuronal cell behavior in vitro, given the limited comparative studies on the effects of graphene family materials on nerve regeneration. Fibrous scaffolds can mimic the architecture of the native extracellular matrix and are potential candidates for tissue engineering peripheral nerves. Silk/GO micro/nanofibrous scaffolds were electrospun with GO loadings $1 \%$ to $10 \%$ wt., and optionally postreduced in situ to explore a family of electrically conductive non-woven silk/rGO scaffolds.

20 Conductivities up to $4 \times 10^{-5} \mathrm{~S} \mathrm{~cm}^{-1}$ were recorded in the dry state, which increased up to $3 \times 10^{-4}$

$21 \mathrm{~S} \mathrm{~cm}^{-1}$ after hydration. Neuronoma NG108-15 cells adhered and were viable on all substrates.

22 Enhanced metabolic activity and proliferation were observed on the GO-containing scaffolds, and these cell responses were further promoted for electroactive silk/rGO. Neurite extensions up to $100 \mu \mathrm{m}$ were achieved by day 5 , with maximum outgrowth up to $\sim 250 \mu \mathrm{m}$ on some of the conductive substrates. These electroactive composite fibrous scaffolds exhibit potential to 
enhance the neuronal cell response and could be versatile supportive substrates for neural tissue engineering applications.

28 Keywords: Neuronal scaffold; silk fibroin; reduced graphene oxide; graphene oxide; electrospinning; neuronal cells

\section{Introduction}

Nerve tissue is electrically sensitive, and the inhibition of electrical signaling can impede normal tissue function. As electrical integrity is essential for this native tissue, one of the main strategies to enhance regeneration is through electrical stimulation [1-3]. Consequently, extensive effort is invested in improving conduction to provide direct electrical activation to enhance cell and tissue function. A particularly interesting option to improve the outcome of nerve repair is the introduction of endogenous electrical regimes within the conduit lumen. Conductivity can be enhanced by facilitating ionic, protonic or electronic transportation depending on the charged carrier [4-6]. Usually, the introduction of electroconductive moieties in tissue constructs is challenging due to aggregation, limited biocompatibility and poor dispersibility [7,8]. Several conjugated polymers (CPs) based on polypyrrole (PPy),

41 polyaniline (PANI) and poly(3,4-ethylenedioxythiophene) (PEDOT) have been previously investigated to provide scaffolds for nerve regeneration with certain levels of conductivity [9]. However, some CPs such as PPy are difficult to further process once synthesized, they are mechanically rigid and brittle, and insoluble after synthesis [10]. Their use in biological applications, as in PANI, is also limited by their low processibility, lack of flexibility and nonbiodegradability [10]. PEDOT, on the other hand, is easily dispersed in aqueous solutions and amenable to solution processing, yet it still shows brittle behavior and tendency to crack, 
based materials (i.e. graphene family nanoplatelets and carbon nanotubes) have received great attention in recent years due to their high versatility and functionality [12].

51 Graphene is a strong candidate for developing scaffolds due to its electrical conductivity [13], mechanical strength [14], topographical features and high surface area [15]. Graphene oxide (GO) is more readily dispersible thanks to oxygen-containing functional groups on its surface, and stands out for its easy processability, high affinity to specific biomolecules [16], and appropriate cell-interface interactions [17]. GO-based substrates can support adhesion, proliferation and differentiation of neurons [18-21] without the use of chemical inducers. Schwann cell secretion of neurotrophic factors has also been promoted on GO substrates [22], along with modulation of stem cell differentiation towards the neural lineage [23-25]. Graphene has demonstrated as well potential to improve neuronal cell responses, including cell attachment, proliferation and stem cell differentiation for neural tissue engineering applications $[26,27]$. In particular, graphene has been shown to promote neuro-specific gene expression, and neurite outgrowth and sprouting in several neuronal-like cells [28-30]. Differentiation of neuronal stem cells into neurons, rather than glia, has also been accelerated on graphene substrates [31]. Schwann cell behavior has also been regulated on graphene-containing substrates by promoting migration, proliferation and myelination [32]. However, the underlying molecular mechanisms behind have remained largely unanswered. Only recently, a study showed that graphene could modulate the active and passive bioelectric properties of the cellular membrane [33].

Most research using graphene family materials are reported on traditional 2D coated surfaces, making them difficult to be developed into suitable 3D assemblies for tissue engineering.

71 Therefore, despite the great potential of the various forms of graphene in neural applications, their use as implantable scaffolds is limited, decreasing their suitability for their clinical 
translation and applicability in more biological contexts. Instead, biohybrids manufactured

74 from the combination of native polypeptides found in nature, along with graphene family materials, can offer a multifactional platform in tissue engineering to develop suitable fibrous scaffolds. Of the many naturally occurring proteins, silks have been extensively investigated in nerve tissue repair and regeneration [34]. In particular, silk fibroin (SF) obtained from Bombyx mori silkworms is widely available as a raw material and easily processable. Silk fibroin has demonstrated great potential due to its physicochemical, mechanical and biological properties: these include aqueous preparation, superior mechanical properties, suitable elasticity, adequate angiogenicity and controlled biodegradability [34,35]. Immobilizing graphene on silk via electrostatic adhesion is common, but thin coatings tend to lack the interfacial adhesion required in between the surfaces since graphene lacks polar groups to induce strong interactions [36]. A way around has been to coat silk fibers with GO instead and reduce it afterwards [37-39], with the interfacial strength arising from the polar groups of GO and the amide groups of silk. However, a thorough post-reduction of the GO coating can weaken the interfacial strength with silk and its conductive stability. More recently, graphene flakes were entrapped in between the silk fibers prior to fiber contraction induced by ethanol immersion [36], but the fiber morphology and underlying topography tend to be lost. In a more recent study, silk fibers were coated on reduced GO (rGO) gels into heterostructured composites towards peripheral nerve repair [40]. However, scale-up and shaping into future nerve conduits may be challenging. Composite blends prior to fiber formation might be a more 93 direct approach.

94 This study explores composite micro/nano- fibrous scaffolds based on SF and GO or reduced 95 GO (rGO). Decoupling the role of conductivity on cell behavior is challenging, since 96 manufacturing scaffolds with similar physico-mechanical properties but different levels of 
conductivity is difficult. Hybrid composites were fabricated here by dispersing GO into an SF solution at increasing controlled loadings $(1 \%, 5 \%$ and $10 \%$ wt.) prior to electrospinning and in situ post-reduction to give electroactive $\mathrm{SF} / \mathrm{rGO}$. Micro/nanofibers with a multiscale structure similar to that of the native extracellular matrix have been widely investigated in nerve tissue engineering due to their suitability for neuronal cell growth. We hypothesize that the presence of (r)GO (i.e. GO or $\mathrm{rGO}$ ) in the system positively influences the neuronal cell response, and that this can be further modulated by the electroactivity attributed to rGO. The biological performance of the scaffolds was assessed with analog neuronal NG108-15 cells over their growth and differentiation phase. To the best of the author's knowledge, this is the

106 first comparative study of silk-based composite micro/nano- fibrous scaffolds with GO and 107 rGO for neural tissue engineering applications.

\section{2. Materials and Methods}

\section{$109 \quad 2.1$ Preparation of silk fibroin}

110 Extraction and purification of silk fibroin from Bombyx mori silkworm cocoons was carried 111 out as previously described [41], with some modifications (Scheme 1A). Briefly, cocoons

112 (Wildfibers, UK) were dewormed, sliced into small pieces, and degummed in a boiling aqueous 113 solution of $0.02 \mathrm{M}$ sodium carbonate $\left(\mathrm{Na}_{2} \mathrm{CO}_{3}\right)$ (Sigma-Aldrich, $\mathrm{UK}$ ) for $60 \mathrm{~min}$. Degummed 114 silk fibroin fibers were thoroughly washed in deionized water (DI water) and air-dried at room 115 temperature overnight. The fibers were then dissolved in 7.9 M aqueous lithium bromide ( $\mathrm{LiBr})$ 116 (Sigma-Aldrich, UK) to form a $16 \% \mathrm{w} \mathrm{v}^{-1}$ solution, under gentle continuous stirring at $60^{\circ} \mathrm{C}$ 117 for $4 \mathrm{~h}$. The resulting solution was centrifuged $(10,000 \times \mathrm{g}, 20 \mathrm{~min})$ and dialyzed (10k MWCO 118 SnakeSkin) (Thermo Fisher Scientific, UK) against 5L of DI water at $4{ }^{\circ} \mathrm{C}$ for $2-3$ days, with 119 regular water changes. The concentration post-dialysis was $\sim 5-6 \% \mathrm{w} \mathrm{v}^{-1}$. The regenerated silk 120 fibroin (SF) solution was centrifuged again, cast onto polystyrene dishes ( $2 \mathrm{~mL}$ of SF solution 
121 per dish) (Sigma-Aldrich, UK) and dried at $60^{\circ} \mathrm{C}$ for $2 \mathrm{~h}$ in a forced air-circulation oven

122 (Memmert Universal, Germany). The resulting films were subsequently peeled off and kept in

123 sealed vials as stock material.

$124 \quad 2.2$ Preparation of silk fibroin/graphene oxide solutions

125 Graphene oxide (GO) flakes (2-DTech, UK) (with lateral dimension and number of layers

126 quoted by the manufacturer as $<4 \mu \mathrm{m}$ lateral width and $<2$ layers) were used as filler. The GO

127 powder was dispersed in $\geq 98 \%$ 1,1,1,3,3,3-hexafluoro-2-propanol (HFIP) (Sigma-Aldrich,

128 UK) (Scheme 1B1) and sonicated at $80 \mathrm{~Hz}$ for $2 \mathrm{~h}$ using a temperature controlled (RT)

129 ultrasonic bath (Elmasonic P60H, Germany). Following sonication, the lateral width of GO

130 flakes was determined as described in the Supplementary Information (S.I). SF films were then

131 dissolved in the GO dispersion by mixing for up to 3 days at $250 \mathrm{rpm}$ in an oil bath heated at

$13250^{\circ} \mathrm{C}$. Solutions of $10 \% \mathrm{w} \mathrm{v}^{-1} \mathrm{SF} / \mathrm{HFIP}$ were obtained at increasing GO loading: control 0, 1 ,

133 5, and 10\% wt. 


\section{A Preparation of stock SF films}

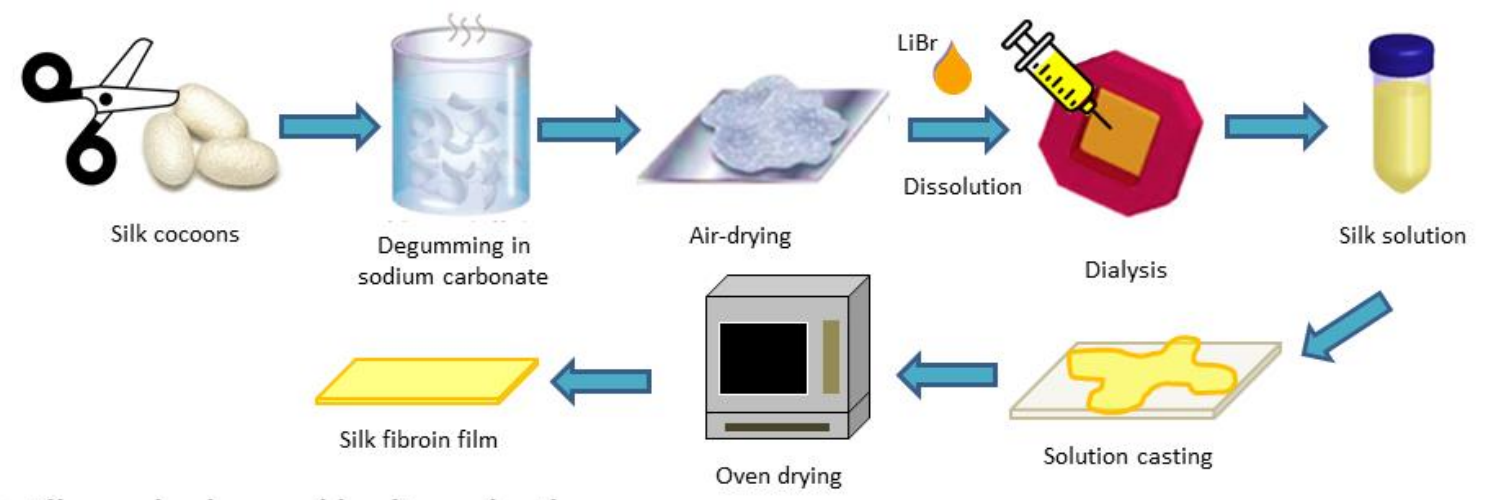

B Fiber spinning and in situ reduction

B.1
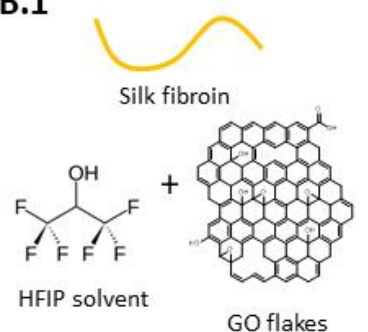

Silk dopes

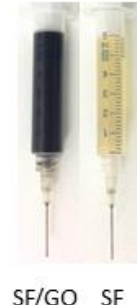

Scheme 1 (A) Schematic of the extraction and synthesis of silk fibroin. (B) Manufacturing of

136 silk-based scaffolds: (B1) Preparation of silk-based dopes for spinning and (B2) schematic of the electrospinning of SF/GO solutions and in situ post-reduction into SF/rGO.

2.3 Fabrication of graphene oxide/silk fibroin fibrous composites and post-reduction treatment

140 Fibrous scaffolds of SF/GO blends were fabricated by electrospinning, giving SF/1G, SF/5G

141 and SF/10G substrates. Briefly, the spinning solution was transferred into a disposable $6 \mathrm{~mL}$

142 Normject $^{\mathrm{TM}}$ syringe (Thermo Fisher Scientific, SG) capped with a 19G blunt metallic needle

143 (0.686 mm inner diameter) (Terumo, SG), fixed in a SP100iZ single-syringe infusion pump

144 (World Precision Instruments, SG). A voltage of $15 \mathrm{kV}$ was generated by a high-voltage DC

145 power supply applied to the needle. A $15 \mathrm{~cm} \times 15 \mathrm{~cm}$ static ground collector covered in

146 aluminum foil was placed at a distance of $10 \mathrm{~cm}$ from the tip of the needle, and the solution

147 was dispensed at a constant rate of $0.8 \mathrm{~mL} \mathrm{~h}^{-1}$. All experiments were performed at room 
148 temperature $\left(\sim 22^{\circ} \mathrm{C}\right)$ with relative humidity $25 \%$ controlled by a dehumidifier device

149 (EuropAce, SG) inside a closed chamber.

150 The substrates were annealed by immersion in a bath of $80 \% \mathrm{v} \mathrm{v}^{-1}$ ethanol for 20 min to induce

$151 \beta$-sheet conformational transition, thoroughly rinsed in DI water, and dried for $24 \mathrm{~h}$ sandwiched

152 between filter paper (Whatman ${ }^{\circledR}$ ) (Sigma-Aldrich, UK) to prevent curling or folding. The

$153 \mathrm{SF} / \mathrm{GO}$ scaffolds were post-reduced in situ (Scheme 1B2) by treating them with a 1\% w/v

154 solution of L-ascorbic acid (Sigma-Aldrich, UK) at $95^{\circ} \mathrm{C}$ for $1 \mathrm{~h}[38,42]$, giving SF/1R, SF/5R

155 and SF/10R substrates. The scaffolds were subsequently washed thoroughly with DI water

156 afterwards. Unmodified SF scaffolds were also treated under similar conditions to use as

157 control.

$158 \quad 2.4$ Characterization of the fibrous composites

159 2.4.1 Morphology and surface topography

160 Fiber morphology and surface topography of different batches of the scaffolds were examined

161 via field emission scanning electron microscopy (FESEM) (JEOL JSM6700F, SG) at $5 \mathrm{kV}$

162 with a working distance of $\sim 8 \mathrm{~mm}$. Fiber diameters were determined manually with Fiji

163 software by measuring a minimum of 100 fibers.

$164 \quad 2.4 .2$ Estimation of porosity and water sorption

165 Water sorption capacity of the scaffolds ( $n=3$ per type) was investigated by weight differences

166 between the hydrated and the dry state (refer to details in the SI). The overall percentage

167 porosity of the scaffolds ( $\mathrm{n}=5$ per type) was determined through gravimetric analysis (refer to

168 details in the SI). The gravimetric estimate of the percentage porosity of the scaffolds was then

169 used to model the pore size through statistical considerations derived by Eichhorn and Sampson

$170[43]$ (refer to details in the SI). 
172 The conformational changes to the secondary structure of silk were evaluated within the spectrum of the amide I region ranging from 1700 to $1600 \mathrm{~cm}^{-1}$, by means of Fourier selfdeconvolution (FSD) as detailed in the SI. The spectrum for each scaffold ( $\mathrm{n}=2$ per type) was taken with a Fourier transform infrared (FTIR) spectrometer (PerkinElmer 2000) equipped with a zinc selenide (ZnSe) crystal on attenuated total reflectance (ATR) mode.

\subsubsection{Electroconductive properties}

178

An automated electrical conductivity and resistivity system (A4P-200 MicroXACT, US) with a Jandel 4-point probe head (Tungsten Carbide tips, $40 \mu \mathrm{m}$ tip radius and $1 \mathrm{~mm}$ tip spacing) (Fig. S1) was used to determine the conductivity $[38,44,45]$ at different positions across the surface of the scaffolds ( $n=4$ per type). Measurements were conducted at room temperature $\left(\sim 20^{\circ} \mathrm{C}\right)$ in the dry state, in the hydrated state, and in the dry state after one-day hydration, as described in the SI.

\subsubsection{Raman spectroscopy}

185 The presence of GO and $\mathrm{rGO}$ within the scaffolds ( $\mathrm{n}=2$ per type) was evaluated using a confocal LabRAM HR Evolution Raman microscope (HORIBA Scientific, SG), by acquiring the Raman spectra at different positions along the surface of the sample (refer to the SI for details).

\subsubsection{Profilometric surface analysis}

189 Differences to the surface topography of the scaffolds ( $\mathrm{n}=2$ per type) were analyzed at room temperature on a Countour GT-K1 3D optical profilometer (Veeco, USA) with light interferometer (refer to the SI for details) [46]. Analysis of the surface roughness was carried out using Vision64 Map ${ }^{\mathrm{TM}}$ (Bruker, USA) software. The arithmetical mean surface height (Sa)

193 and root mean square surface height $(\mathrm{Sq})$ parameters of the 3D profile ordinates were analyzed

194 for each image taken, and the average values for each sample type determined. 
196 The capacity of the scaffold ( $\mathrm{n}=3$ per type) to adsorb protein was evaluated using Engelbreth-

197 Holm-Swarm murine laminin (Sigma-Aldrich, UK) and the NanoOrange ${ }^{\circledR}$ protein

198 quantification kit (Thermo Fisher Scientific, UK), based on the amount of remaining protein in

199 solution after adsorption (refer to the SI for details). Fluorescence intensity was read (ex./em.

200 485/590 nm) with a FLUOstar Optima microplate reader (BMG Labtech).

\subsection{In vitro study}

\subsubsection{Cell culture of neuronoma NG108-15}

203 In vitro cell culture experiments were conducted using a NG108-15 neuroblastoma $\times$ glioma

204 rat/mouse hybrid neuronal-like cell line (ATCC, UK). Cells were subcultured in CellStar ${ }^{\circledR}$ 205 tissue culture polystyrene (TCP) treated T25-75 flasks (Greiner Bio-One, UK). Cells were 206 grown with high glucose $\left(4.5 \mathrm{mg} \mathrm{mL}^{-1}\right)$ Dulbecco's modified Eagles medium (DMEM-HG)

207 containing L-glutamine and without sodium pyruvate (Sigma-Aldrich, UK), $10 \% \mathrm{v} \mathrm{v}^{-1}$ fetal 208 bovine serum (FBS) (Sigma-Aldrich, UK), 1\% v v ${ }^{-1} 100 \times$ penicillin-streptomycin (Pen/Strep) solution (10,000 IU Pen and 10,000 $\mathrm{g} \mathrm{mL}^{-1}$ Strep) (Sigma-Aldrich, UK), and supplemented with a HAT 50× solution (Thermo Fisher Scientific, UK) to a final working concentration of $100 \mu \mathrm{M}$ hypoxanthine, $0.4 \mu \mathrm{M}$ aminopterin, and $16 \mu \mathrm{M}$ thymidine. Cells were cultured in a

212 humidified atmosphere incubator at $37^{\circ} \mathrm{C}\left(5 \% \mathrm{CO}_{2}\right.$ and $95 \%$ air), with half of the medium

213 changed every 2 days. Cells were used between passage P17-30 after they became 70-80\% 214 confluent.

215 For cell culture experiments, scaffolds (13 $\mathrm{mm}$ diameter) were clipped to CellCrown ${ }^{\mathrm{TM}}$ polycarbonate inserts (Scaffdex Oy, Finland) for 24-well plates (vol. $1 \mathrm{~mL}$ ). Mounted annealed

217 scaffolds were maintained in sterile molecular biology grade water for approximately $24 \mathrm{~h}$ prior 218 to cell culture. The scaffolds were sterilized with $70 \% \mathrm{v} \mathrm{v}^{-1}$ ethanol for $30 \mathrm{~min}$, followed by a 
21930 min wash in sterile PBS, transferred into sterile, low-binding 24-well plates (Corning, UK) and exposed to UV-light for $20 \mathrm{~min}(254 \mathrm{~nm})$ inside a biosafety cabinet. Glass coverslips (CV)

221 (12 mm diameter, 0.13-0.16 mm thickness) (VWR, UK) were used as positive controls. To 222 improve cell adhesion, scaffolds were preconditioned overnight in supplemented medium to 223 promote protein adsorption and facilitate cell attachment. Prior to cell seeding, scaffolds were 224 air-dried inside a biosafety cabinet for $60 \mathrm{~min}$ to ensure that the cell suspension would not 225 spread around. A cell seeding density of 10,000 cells per well within a $\sim 50 \mu \mathrm{L}$ droplet was used, and the scaffolds were left to adhere for 60 min inside an incubator before adding fresh media. Half of the media was changed every 2 days.

\subsubsection{Cell survival}

Cellular viability of the various cell-laden scaffolds ( $n=2$ per type) was evaluated at days 3,5 and 7 using a LIVE/DEAD ${ }^{\circledR}$ viability/cytotoxicity fluorescence kit (Thermo Fisher Scientific, UK) (refer to the SI for details). 3D imaging was carried out using a TCS SP8 confocal laser scanning microscope (Leica Microsystems Ltd., UK) at an ex./em. of 494/517 nm for live cells and 528/617 $\mathrm{nm}$ for dead cells. Z-stacking images were acquired by scanning three different areas throughout the thickness of each scaffold at $5 \mu \mathrm{m}$ per Z-step. Cell quantification was carried out with Fiji software. Data is expressed as the percentage of live cells versus nonviable/dead cells.

\subsubsection{Metabolic activity and cellular proliferation}

238 The metabolic activity of cell-laden scaffolds ( $\mathrm{n}=4$ per type) was monitored on days 3, 5 and 7

239 using the alamarBlue ${ }^{\mathrm{TM}}$ reduction assay according to the manufacturer's instructions (refer to 240 the SI for details). The fluorescence (ex./em. 544/590 nm) was measured with a FLUOstar 241 Optima microplate reader (BMG Labtech, UK), and recorded as a function of the dsDNA content to give an indication of the metabolic activity relative to the number of cells. 
243 Cellular proliferation of the same samples at similar time points was then measured by the

244 Quant-iT ${ }^{\mathrm{TM}}$ PicoGreen ${ }^{\circledR}$ dsDNA assay (Thermo Fisher Scientific, UK) (refer to the SI for

245 details). The fluorescence (ex./em. 485/520 nm) was measured with a FLUOstar Optima

246 microplate reader (BMG Labtech), and compared with a generated lambda dsDNA standard

247 curve obtained within the range of measured concentrations. The cell number was estimated

248 based on the assumption that a single cell contains around 5 pg of DNA.[47]

\subsubsection{Neuronal differentiation}

250 To induce neuronal differentiation, the cell culture medium was changed to a differentiation medium one day post-seeding, using serum-free medium. The culture was maintained for 5 days, with half of the medium removed and replaced with fresh medium every 2 days.

\subsubsection{Immunocytochemistry (ICC)}

254 Cell-laden scaffolds ( $\mathrm{n}=2$ per type) were harvested, gently washed twice with PBS and treated with $10 \% \mathrm{v} \mathrm{v}^{-1}$ neutral buffered formalin (NBF) (Sigma-Aldrich, UK) (equivalent to about 4\% $\mathrm{w} \mathrm{v}^{-1}$ paraformaldehyde) overnight at $4^{\circ} \mathrm{C}$ as fixative solution. Samples were rinsed three times with PBS, permeabilized with $0.1 \% \mathrm{v} \mathrm{v}^{-1}$ Triton X-100 in PBS for 15 min and further rinsed three times with PBS. Samples were then blocked for non-specific binding with $1 \% \mathrm{w} \mathrm{v}^{-1}$ bovine serum albumin (BSA) in PBS for 30 min and rinsed three times with PBS.

To assess the differentiation of neuronal cell bodies, cell-laden samples were labeled with

261 polyclonal rabbit anti-mouse/rat ß-tubulin III (Abcam, UK) as primary antibody, and 262 preadsorbed polyclonal goat anti-rabbit IgG H\&L Alexa Fluor ${ }^{\circledR} 488$ (Abcam, UK) as secondary 263 antibody. Samples were incubated at a 1:1000 v v dilution in PBS for $2 \mathrm{~h}$ at room temperature, 264 respectively; PBS was used to rinse in between steps. Cell nuclei were counterstained with 4',6-diamidino-2-phenylindole dihydrochloride (DAPI) blue $\left(1 \mathrm{mg} \mathrm{mL}^{-1}\right)$ (Sigma-Aldrich,

$266 \mathrm{UK}$ ) at a 1:1000 $\mathrm{v} \mathrm{v}^{-1}$ dilution in molecular biology grade water for $2 \mathrm{~min}$ at room temperature. 
267 Samples were finally rinsed again with PBS three times. The volume of solution was $\sim 200 \mu \mathrm{L}$ 268 per sample to ensure they were completely submerged.

269 Samples were mounted for imaging on Fisherbrand ${ }^{\mathrm{TM}}$ glass microscopic slides $(76 \times 26 \mathrm{~mm}, 0.8$ -

$2701 \mathrm{~mm}$ thickness) (Fisher-Scientific, UK) using ProLong ${ }^{\circledR}$ Diamond Antifade Mountant

271 (Thermo Fisher Scientific, UK); an appropriate sized glass coverslip (18×18 mm, 0.13-0.17

272 mm thickness) (VWR, UK) was then placed over the section of interest and cured at room

273 temperature overnight following the manufacturer's instructions. Samples were imaged using

274 a TCS SP8 confocal laser scanning microscope (Leica Microsystems, UK) at an ex./em. of $275340 / 488 \mathrm{~nm}$ for DAPI and 495/519 nm for Alexa Fluor ${ }^{\circledR} 488$. Z-stacking images were acquired 276 by scanning different areas throughout the thickness of the scaffold at $5 \mu \mathrm{m} / \mathrm{Z}$-step. Images 277 were visualized using Fiji software.

\subsubsection{Neurite outgrowth}

279 Average neurite length, maximum neurite extension and average number of neurites per neuronal cell body for each scaffold type were analyzed from immunofluorescent micrographs.

281 Only extended structures longer than $30 \mu \mathrm{m}$ (measured from the middle of the cell body until

282 the end of the projection) were considered as neuronal processes. High-magnification images

283 were sampled from randomly selected fields of view, with a minimum of 10 neurites analyzed.

284 Quantification was carried out using Fiji software.

\section{$285 \quad 2.6$ Data analysis}

286 Statistical analysis was performed with GraphPad Prism 8 (San Diego, USA), and datasets

287 checked for normality. Normally distributed data is presented as standard deviation (SD, error bars) of the mean values. For parametric data and multiple comparisons, significance was assessed by one-way ANOVA (one independent variable) or two-way ANOVA (two independent variables) with Tukey's post hoc analysis test. Not normally distributed data was 
assessed by Kruskal-Wallis with Dunn's post hoc analysis test. A value of $p<0.05$ was considered statistically significant.

\section{3. Results and Discussion}

294 Dissolution of silk fibroin is an important step in reprocessing it into fibers, but there are limited 295 suitable solvents [48]. Here, we dispersed GO in HFIP, followed by sonication, silk fibroin 296 addition and dissolution as described in the methodology. The distribution of the lateral width

297 of GO flakes after $2 \mathrm{~h}$ sonication is shown in Fig. S2, with an average size of $167( \pm 54) \mathrm{nm}$.

298 Longer sonication times can undermine the mechanical properties of GO, primarily attributed

299 to a more aggressive fragmentation of the flakes resulting in an increased oxidation degree and

300 the presence of more inter junctions and defects [49-51]. With this in mind, it was important 301 to optimize a well-dispersed blended SF/GO solution, where the GO flakes could be effectively electrospun alongside silk fibroin to form bead-free fibers (Fig. S3).

\section{$303 \quad 3.1$ Fibrous morphology}

304 The surface topographies and morphologies of the composite silk-based scaffolds are shown in Fig. 1A. Unmodified silk scaffolds appeared whitish in color. Composite silk scaffolds were rendered increasing brown with increased GO loadings. After in situ post-reduction into $\mathrm{SF} / \mathrm{rGO}$, the samples turned into various shades of grey tending to black. Morphology of the fibers, as observed under FESEM, was smooth and consistent for every group tested, with an average fiber diameter of around $800 \mathrm{~nm}$ (Fig. 1B). A decrease in the average fiber diameter due to larger fiber elongation during spinning has been reported with the incorporation of

311 graphene and its derivatives [52,53]. While some differences could be observed compared with

312 unmodified silk, fibers of similar diameter size were obtained with addition of GO up to $10 \%$ 313 wt. - all blended solutions spun at similar conditions. Fiber diameter was not significantly

314 affected by post-spinning annealing, but moderately increased $(\mathrm{p}<0.01)$ after post-reduction 
315 with ascorbic acid. In this respect, Huang et al. investigated the effects of different reducing

316 agents on the properties of wet-spun GO fibers, and reported hydroiodic acid to result in lower

317 fiber diameter, whereas hydrazine treatment caused larger diameters [54].

\section{$318 \quad 3.2$ Porosity and water sorption}

319 Scaffolds manufactured by electrospinning usually consists of densely packed fibers with

320 limited inter-fiber spacing and pore diameter [46]. However, a certain level of porosity is

321 required in nerve conduits to allow infiltration of blood vessels and regulate nutrient uptake,

322 oxygen diffusion and waste exchange [55]. Previously reported data has shown that the

323 addition of carbon-based nanomaterials can lead to an increase in the pore diameter and overall

324 scaffold porosity [56,57]. Following the determination of the percentage porosity, it was clear

325 that the presence of (r)GO did not result in this case in major changes in the overall porosity

326 (70-80\%) or the estimated pore dimensions $(\sim 15 \mu \mathrm{m})($ Fig. 1C-D), and that these are a good

327 compromise to provide a cell-friendly conduit lumen [55]. Indeed, scaffolds with excessive

328 pore diameters may facilitate infiltration of non-neural cells along the conduit length and hinder

329 neurite outgrowth [55]. In particular, pore diameters $<30 \mu \mathrm{m}$ in the conduit lumen are ideal to

330 inhibit the invasion of fibroblasts and macrophagocytes for the regeneration of peripheral nerve

$331 \quad[58]$.

332 

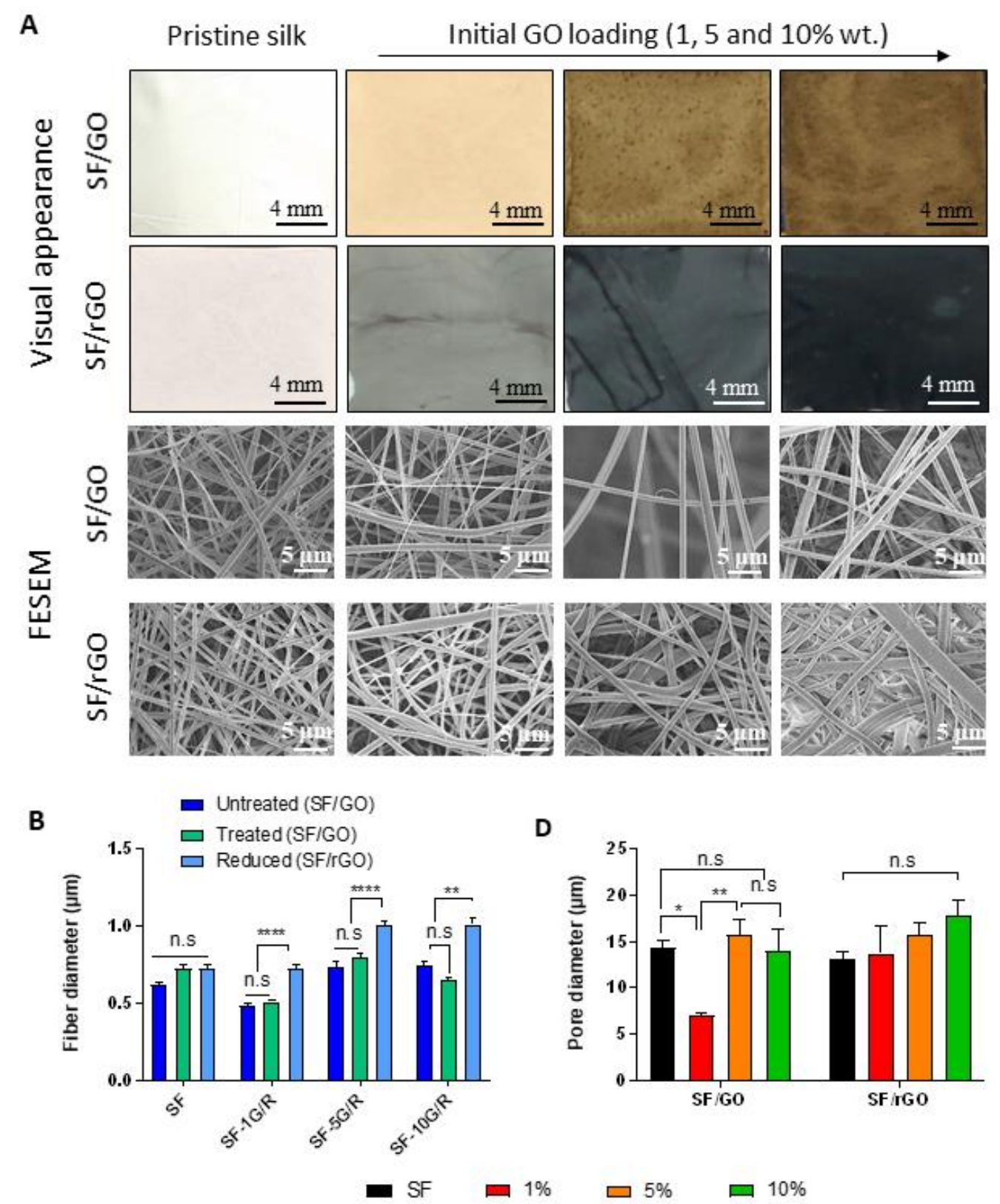

C

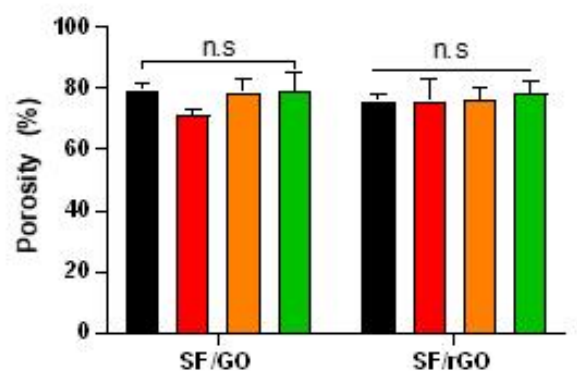

E

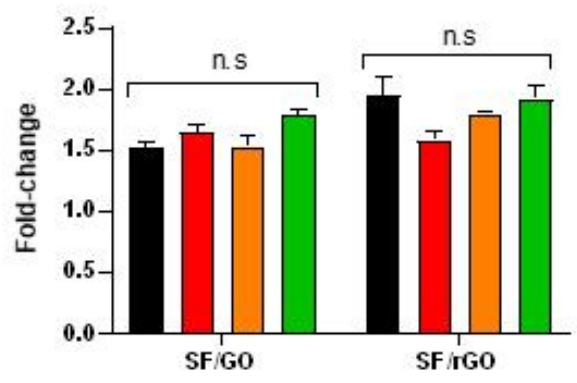

334 Fig. 1 Effect of (r)GO content on the scaffold structure. (A) Representative macroscopic views

335 of the visual appearance of the scaffolds prior to and after post-reduction, and representative

336 FESEM micrographs of the scaffolds; scale bars at $4 \mathrm{~mm}$ and $5 \mu \mathrm{m}$ respectively. (B) 
337 Distribution of the fiber diameter size of the scaffolds before and after ethanol treatment 338 (annealing) and with post-reduction ( $\mathrm{n}=100$ fibers). $(\mathbf{C})$ Overall porosity of the scaffolds ( $\mathrm{n}=5$

339 per type) and (D) estimated average pore diameter. (E) Water sorption of the scaffolds (n=3

340 per type) after overnight incubation at physiological conditions. Differences between the

341 experimental groups were analyzed by two-way ANOVA with Tukey's test, or by Kruskal-

342 Wallis with Dunn's test. n.s non-significant, * $\mathrm{p}<0.05, * * \mathrm{p}<0.01, * * * * \mathrm{p}<0.0001$.

343 Water sorption is an also an important feature that can influence the properties of the substrate

344 prior to and after implantation. For instance, the void space might be reduced, increasing direct

345 contact between the cells and the material [59]. Although silk fibroin presents a polymeric

346 structure with hydrophobic regions, it has large sorption capacity to hold moisture thanks to its

347 alternating hydrophilic regions [60]. Enhanced hydrophilicity can lead to increased cell

348 attachment [61]. While the hydrophilicity/hydrophobicity of graphene and its derivatives has

349 remained under constant debate over the last few years, it has been recently demonstrated that

350 when graphene is placed in a water-like environment, it presents hydrophilic properties close

351 to those of pure water [62]. Here, all substrates showed great water sorption capability; while

352 some changes were observed with the presence of (r)GO in the fibers, these differences were

353 non-significant (Fig. 2C).

\section{$354 \quad 3.3$ Molecular structure of silk and the effect of graphene derivatives}

355 The addition of (r)GO into the silk system has previously been reported to lead to changes in

356 the amount of $\beta$-sheet structures after ethanol treatment [63-65]. The chemical structure of SF

357 was analyzed by FTIR-ATR (Fig. 2A). There was no obvious difference in the spectra, which

358 indicates no generation of new groups. Since the (r)GO content is low compared with that of

359 SF, and some of their characteristic peaks are very close, it is difficult to analyze the (r)GO-SF

360 interactions from the FTIR spectra. Therefore, the proportion of secondary structures within 
361 the amide I region was quantified by means of deconvolution (Fig. 2B). As expected, the amount of $\beta$-sheet structures increased after ethanol treatment due to increased crystallization

363 resulting from the transition of $\alpha$-helix into $\beta$-sheet [66]. Indeed, it has been suggested that the 364 mobility of the polypeptide chains is likely to be reduced as ethanol strips off the water shell 365 around fibroin, resulting in an increased rate of $\beta$-sheet formation [67]. The amphiphilic 366 properties of GO could maximize hydrogen bonding, polar-polar, and hydrophobic367 hydrophobic interactions with SF, which is composed of polar random domains and 368 hydrophobic $\beta$-sheets. Furthermore, electrostatic interactions and hydrogen bonding between 369 SF and GO can stabilize crystal structures and facilitate the formation of fibril structures [68]. 370 However, it has also been reported that the introduction of GO can confine SF crystallization, 371 leading to a decrease in crystallinity and crystallite size, and the formation of new interphase zones [64] (i.e. an oriented amorphous zone and the interface zone between SF and GO due to interfacial interactions between the hydrophilic blocks of SF and the oxygen groups of GO [68]). Here, a similar proportion of the various secondary structures were quantified on the substrates at the different GO loadings (Fig. 2B), with a slight reduction in the $\beta$-sheet content

376 (p-value non-significant) at increased GO inclusion. These results tend to agree with those by Zhang et al. [64]. A similar proportion of the secondary structures were quantified for the various samples after in situ post-reduction into SF/rGO (Fig. 2B), with no significant differences with regards to the crystalline $\beta$-sheet content similar to the work of Zulan et al.

380 [37]. Overall, similar silk-based scaffolds with no major changes in the molecular structure of 381 silk were manufactured regardless of the addition of (r)GO. This is indeed important to help 382 decoupling the influence of GO and rGO in subsequent cell-based assays.

383 Further studies were carried out to understand the compositional distribution of the fibers, 384 where the presence of GO and rGO was confirmed by Raman spectroscopy (Fig. 2C). The 
385 Raman spectra of the GO-containing scaffolds displayed two prominent peaks at around 1330

$386 \mathrm{~cm}^{-1}$ and at $1595 \mathrm{~cm}^{-1}$, ascribed to the $\mathrm{D}$ and $\mathrm{G}$ bands respectively. The $\mathrm{G}$ band is characteristic

387 of sp2-hybridized $\mathrm{C}-\mathrm{C}$ bonds in a two-dimensional hexagonal lattice, while the D band 388 corresponds to the defects and disorder in the planar carbon network [69]. For the case of the

389 rGO-containing scaffolds, the D band slightly retracted towards $1315 \mathrm{~cm}^{-1}$, while the $\mathrm{G}$ band

390 did not revealed any changes. A characteristic band attributed to $\beta$-sheets [38] could be

391 observed at around $1670 \mathrm{~cm}^{-1}$ for unmodified silk, and the absence of graphene in these fibers

392 was demonstrated by the lack of the characteristic spectral bands. The D/G intensity ratio can

393 also be used as an indicator of the defects in the graphene structure. In this study, the intensity

394 ratio of the samples (Fig. 2D) was found to increase with the filler content, which can be

395 correlated to increased carbonaceous presence in the composites [38]. The intensity ratio

396 decreased for rGO-containing samples, which could be attributed to a decreased amount of

397 oxygenated groups or structural defects after the reduction process [70,71]. 
A

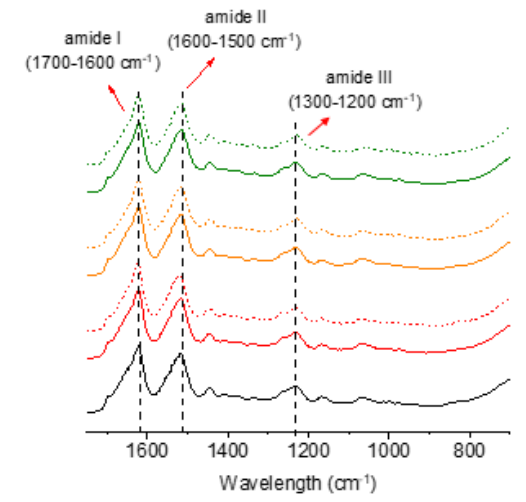

$-\mathrm{SF}$

$-\mathrm{SF} / 1 \mathrm{G} \quad-\mathrm{SF} / 5 \mathrm{G} \quad-\mathrm{SF} / 10 \mathrm{G}$

...SF/1R …SF/5R …SF/10R

$$
\text { D band G band }
$$

C

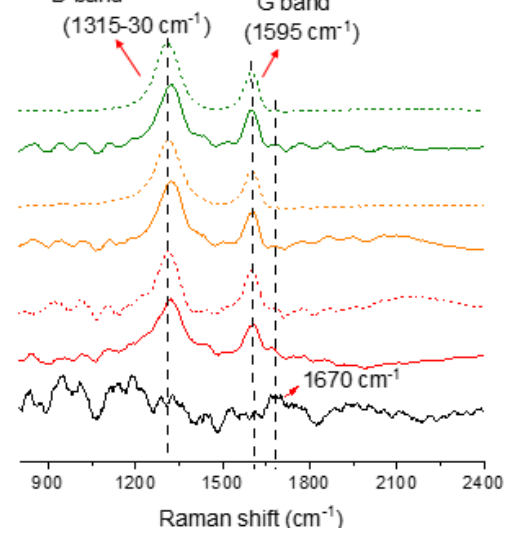

B

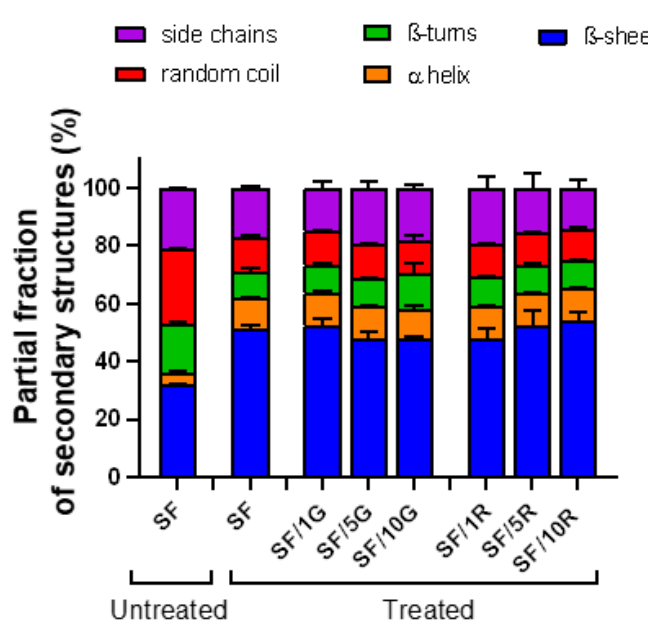

D

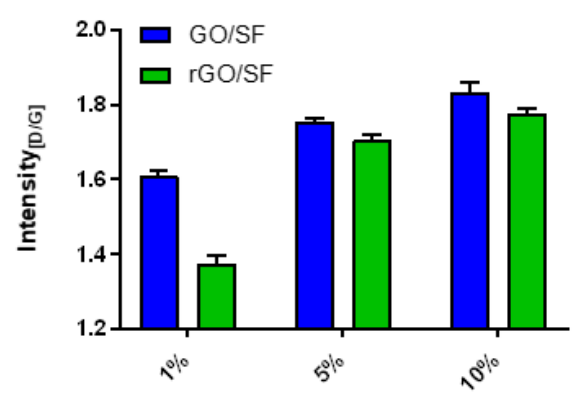

Fig. 2 Effect of the presence of (r)GO on the chemical structure of silk. (A) Representative

400 FTIR spectrum of the various scaffolds showing the typical fingerprint of silk. (B) Quantitative analysis of the secondary structure composition of silk, before and after treatment, within the amide I region (1700-1600 $\left.\mathrm{cm}^{-1}\right)$. (C) Representative Raman spectra of the scaffolds. (D)

403 Intensity ratio of the D and G spectral bands.

\section{$404 \quad 3.4$ Conductive properties}

405 Electrical conductance is dependent upon various factors, such as hydration degree, solvent or 406 doping agent presence [44]. In this study, rGO flakes act as high aspect ratio electroconductive

407 fillers in biohybrid composite electrospun silk-based scaffolds. Well-dispersed flakes within 408 the fibers can contribute to the formation of conductive networks, generating self-assembling 409 conductive pathways by forming conduction anchor nodes throughout. These conductive 
410 pathways facilitate and enhance electronic transport, along with protonic (e.g. molecules of

411 bound water and amino acid side groups of proteins [72]) and ionic (e.g. electrolytes from the

412 medium; the conductivity of cells is ionic in nature) currents throughout the substrate. Cell-cell

413 communication in electrically sensitive tissues can be enhanced this way. For instance, it has

414 been shown that hydrogels synthesized in combination with multi-walled carbon nanotubes

415 [56] or PEDOT-PSS [73] can act as internal enhanced electrical systems to promote the cell

416 response. In both studies, cell-cell communication between cardiomyocytes was facilitated by

417 enhancing the overall substrate's conduction and inducing cell elongation and unidirectional

418 cell alignment with improved coupling and beating.

419

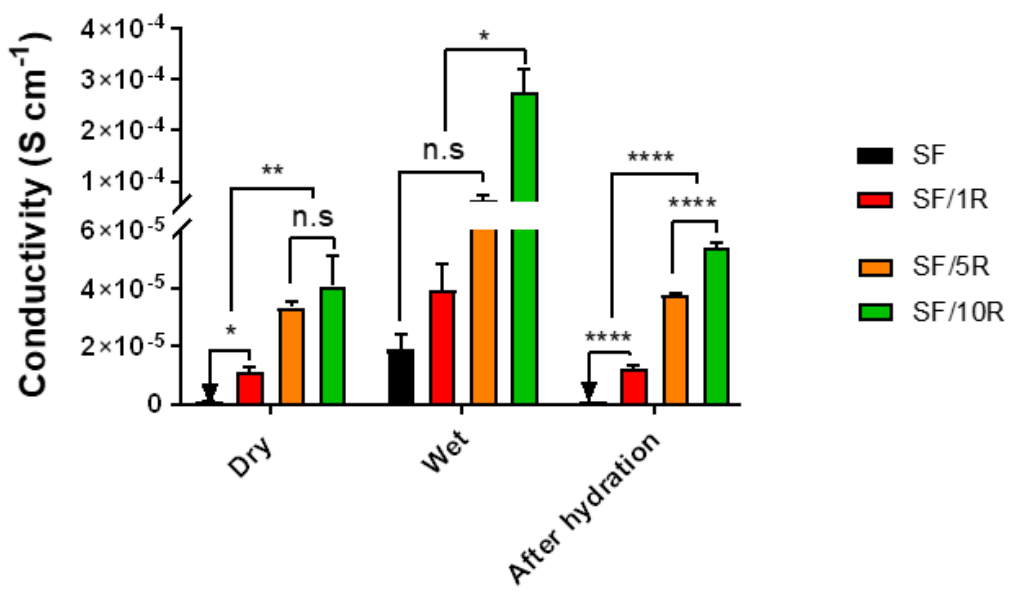

420 Fig. 3 Conductivity of electroactive SF/rGO scaffolds. Quantitative analysis of the 421 conductivity properties of the scaffolds ( $n=4$ per type) in the dry state, in the hydrated state and 422 in the dry state after one-day hydration. Differences between the experimental groups were analyzed by two-way ANOVA with Tukey's test. n.s non-significant, ${ }^{*} \mathrm{p}<0.05$, $* * \mathrm{p}<0.01$, $* * * * \mathrm{p}<0.0001$.

Conductivity of SF/GO (Fig. S4) and electroactive SF/rGO scaffolds (Fig. 3) was estimated with a 4-point probe station. As expected, low conductivities were recorded on SF/GO scaffolds. Some differences were observed following addition of GO, though, in agreement 
with a previous study on protein-based hydrogels with GO incorporation [74]. Reduced GO offers higher electrical conductivity in comparison to GO for applications where tuning electrical properties is the main target. The presence of rGO increased the overall conductivity up to $\sim 4 \times 10^{-5} \mathrm{~S} \mathrm{~cm}^{-1}$ in the dry state, and peaked at $\sim 3 \times 10^{-4} \mathrm{~S} \mathrm{~cm}^{-1}$ in the hydrated state. This was a synergic effect provided by both the substrate (electronic and protonic conductivity) and the electrolytes of the medium (ionic conductivity), and differs from the trend previously reported by Martins et al. where the conductivity of a carbon nanofiber/chitosan scaffold was dominated by the aqueous media and decreased upon hydration [75]. However, even in those cases where the ionic conductivity provided by the aqueous environment could dominate over substrates of lower inherent conductivity [75], local changes in conductivity attributed to the electroconductive/active moiety may directly affect the properties of cells by altering their resistance or capacitance. Hydrated protein-based materials [5,76-79], in this case silk fibroin [80], can also be considered as proton conductors. Water-mediated proton hopping takes place due to peptide and peptenol flip-flopping [80], and is known as the Grotthuss mechanism [5]. The electroactive SF/rGO scaffolds maintained their original conductivity in the dry state after one-day hydration.

On the other hand, rGO offers limited conductivity due to the presence of defects on the carbon backbone and the small flake size achieved during processing. Furthermore, high conductivity is subjected to achieving percolation threshold and a successful dispersion of the flakes within

447 the polymer matrix. Although the conductivity exhibited here for most SF/rGO samples 448 (dry/hydrated states) may fall short [81], it has been reported that a range $1 \times 10^{-6}$ to $8 \times 10^{-5} \mathrm{~S}$ $449 \mathrm{~cm}^{-1}$ is sufficient for conducting electrical regimes in vivo [82,83]. The conductivities 450 exhibited here in the dry/hydrated state fall within such range and exceed it, and could even be 
further tuned to match or even surpass native tissues' conductivity by incorporating pristine graphene [84].

\subsection{Neuronal cell viability, metabolic activity and proliferation}

454 Neuronal-like cells were seeded onto all sample groups and their viability, metabolic activity and proliferation profiles evaluated. A viability assay was used to assess potential cytotoxicity of the different scaffolds, as well as evaluate attachment and survival of NG108-15 cells.

457 Representative confocal micrographs and semi-quantitative analysis of viable and non-viable 458 cells are shown in Fig. 4 and Fig. S5. In all substrates, few dead cells were observed, with the 459 great majority being alive (Fig. 4A). The percentage of viable cells after 7 days of culture was $460>95 \%$ for all scaffolds (Fig. 4B). No major differences in the ratio of viable cells were observed 461 among the different substrates and the controls, demonstrating that the presence of GO or rGO 462 in the system up to $10 \%$ wt. does not induce any major cytotoxic effects in vitro. During the 463 growth phase, cells were observed to present round shapes with limited processes along their 464 surface and grew clustered together in colonies. This is typical of NG108-15 cells and may 465 have been further promoted by the randomly distribution of the fibers. 

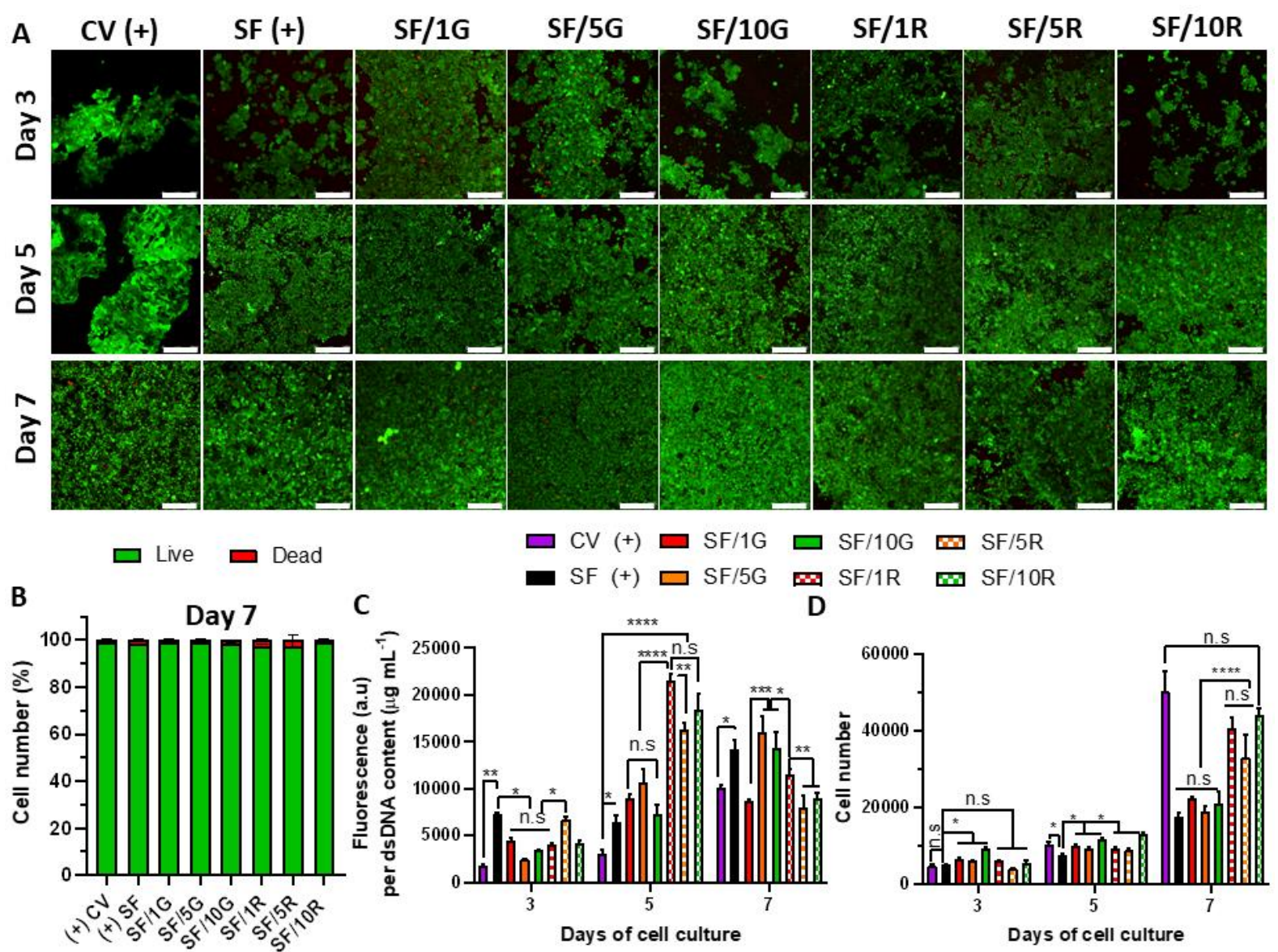

467 Fig. 4 In vitro cellular viability, metabolic activity and proliferation of NG108-15 cell-laden 468 scaffolds over 7 days of culture: glass coverslip (CV), silk fibroin (SF), 1\% GO/SF (SF/1G), $4695 \% \mathrm{GO} / \mathrm{SF}(\mathrm{SF} / 5 \mathrm{G}), 10 \% \mathrm{GO} / \mathrm{SF}(\mathrm{SF} / 10 \mathrm{G}), 1 \% \mathrm{rGO} / \mathrm{SF}(\mathrm{SF} / 1 \mathrm{R}), 5 \% \mathrm{rGO} / \mathrm{SF}(\mathrm{SF} / 5 \mathrm{R})$ and $47010 \% \mathrm{rGO} / \mathrm{SF}$ (SF/10R). (A) Representative confocal micrographs of cells labeled with calcein 471 AM (green) and ethidium homodimer-1 (red) as markers of cell viability; scale bars at $250 \mu \mathrm{m}$.

472 (B) Semi-quantitative analysis of the percentage of viable and non-viable cells after 7 days in 473 culture ( $\mathrm{n}=2$ scaffolds per type). (C) Metabolic activity relative to dsDNA content ( $\mathrm{n}=4$ 474 scaffolds per type) and (D) cellular proliferation ( $\mathrm{n}=4$ scaffolds per type) of undifferentiated 475 cells. Differences between the experimental groups were analyzed with two-way ANOVA with 476 Tukey's test. n.s non-significant, ${ }^{*} \mathrm{p}<0.05,{ }^{* *} \mathrm{p}<0.01, * * * * \mathrm{p}<0.0001$. 
477 Many studies have investigated the toxicology profiles of graphene-family nanomaterials in 478 vivo following different administration routes, as reviewed in [85]. Toxicology-mechanisms in 479 vivo of graphene-family nanomaterials may include oxidative stress, DNA damage or 480 inflammatory response amongst others. However, these are all largely influenced by the 481 dose/concentration, lateral dimension/size, surface structure or functionalization degree, 482 always leading to inconsistent results amongst different studies [85]. Their excretion and 483 clearance from the body vary among different organs, but renal and fecal routes appear to be 484 the main elimination routes [85]. Most experiments to date have focused on assessing toxicity 485 in the lung and liver, and toxicity in the peripheral nervous system deserves more attention. 486 Recent in silico toxicity screening studies of graphene-containing silk-based materials confirm 487 skin sensitization due to the presence of conjugated dienes in their structures [86], but at much 488 higher loading concentrations (> 10\% wt.) than the ones used in the current study.

489 The metabolic activity of NG108-15 cells relative to the number of cells in culture is presented 490 in Fig. 4C. Cells exhibited greater metabolic activity on substrates containing GO and rGO 491 compared to unmodified silk, tending to increase with filler content. By day 5, cells grown on 492 electroactive SF/rGO samples were metabolically more active than those grown on SF/GO, 493 while by day 7 the trend was opposite, which might suggest cell confluency. The metabolic 494 activity results were well supported in terms of cellular proliferation on the various substrates over time (Fig. 4D), with the SF/rGO scaffolds accelerating cellular proliferation to the greatest extent. These differences in cellular behavior could be directly attributed to the presence of 497 electroactive $\mathrm{rGO}$ as opposed to GO.

498 Nevertheless, surface roughness and protein adsorption can also affect cell-material 499 interactions [87], leading to changes in cellular adhesion, proliferation and biosynthesis of 500 ECM components. Addition of (r)GO into the silk system led to a significant increase 
501 ( $\mathrm{p}<0.001)$ in surface roughness for all samples tested (Fig. 5A, and Fig. S6) compared to 502 unmodified silk. Similarly, previous reports have shown increased surface roughness at 503 increased graphene [84], carbon nanofiber [88] and carbon nanotube [89] content within

504 various composites. Such changes may lead to regionally organized micro/nano- topographies 505 that can contribute to micro/nano- structure-induced cellular interactions [89]. Non-significant 506 differences in surface roughness were observed between the GO and rGO counterparts prior to 507 and after post-reduction. The ability of the scaffolds to adsorb protein was also quantified (Fig.

508 5B). Protein adsorption tended to increase especially at increased (r)GO loading compared with 509 unmodified silk. This is in agreement with other studies $[88,90]$ that have correlated an increase 510 in protein adsorption with an increase in surface roughness. However, regardless of the GO 511 and rGO counterparts presenting similar surface roughness, lower amounts of laminin were 512 adsorbed on the rGO-containing samples. These results are in line with previous findings that 513 have demonstrated that GO shows greater adsorption of proteins on its surface compared with 514 rGO [91-93]. Therefore, while some studies have suggested that surface roughness and protein 515 adsorption can be more vital traits over the electronic configuration of the scaffold [6], the 516 tendency of electroactive SF/rGO to outperform SF/GO substrates in terms of the cellular 517 response (Fig. 4C-D) could be attributed here to the endogenous electrical regimes induced by 518 rGO. 
A

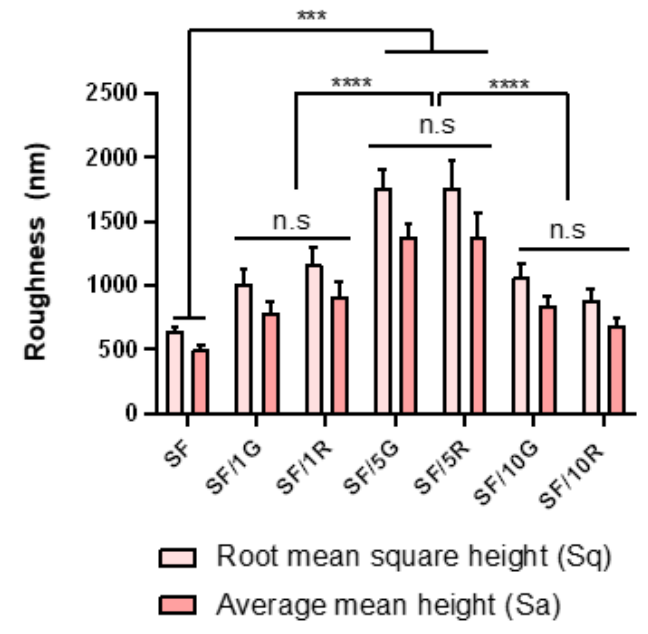

B

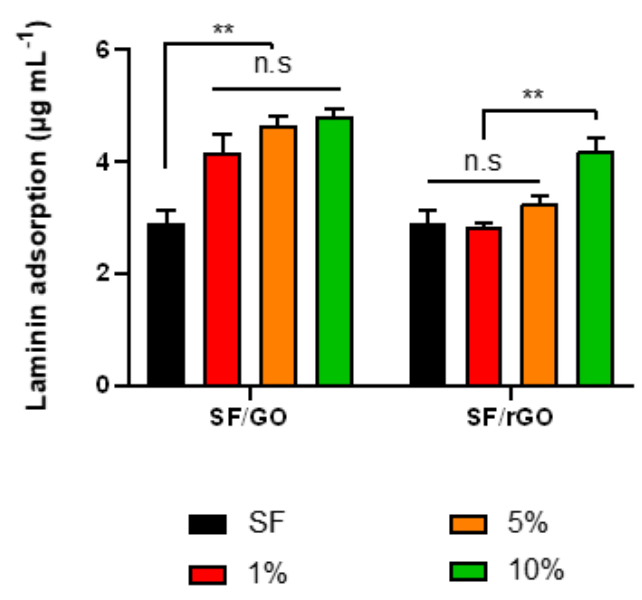

520 Fig. 5 Surface roughness and protein adsorption on the scaffolds. (A) Quantitative analysis of

521 the surface roughness parameters ( $\mathrm{Sq}$ - root mean square height, and $\mathrm{Sa}$ - average mean height)

522 of the scaffolds ( $\mathrm{n}=2$ per type). (B) Quantitative analysis of laminin adsorption on the scaffolds

523 ( $\mathrm{n}=3$ per type) after $2 \mathrm{~h}$ incubation. Differences between the experimental groups were

524 analyzed by two-way ANOVA with Tukey's test. n.s non-significant, ${ }^{* *} \mathrm{p}<0.01,{ }^{* * *} \mathrm{p}<0.001$,

$525 * * * * \mathrm{p}<0.0001$

\subsection{Neuronal differentiation}

527 Neurite outgrowth, axonal elongation and the formation of neuronal circuits are essential for

528 the nerve tissue repair and regeneration process. Neurite outgrowth can be guided by physical

529 cues in the substrate, but also directed by electrical regimes. Inspired by the cell metabolic

530 activity and proliferation results, NG108-15 neuronal-like cells were grown on the various

531 scaffolds in serum-deprived conditions and immunolabeled with $\beta$-tubulin III as a marker for

532 neurite outgrowth and differentiation (Fig. 6). $\beta$-tubulin III is a marker expressed in neuronal

533 cell bodies, dendrites, axons, and axonal terminations. Cell-laden samples in serum-

534 supplemented medium served as negative controls of differentiation (Fig. S7), with cells 
535 growing very clustered together without neurite extension. Representative micrographs of the

536 various cell-laden substrates after induced differentiation are shown in Fig. 6A. Neurite

537 outgrowth on all substrates could be clearly observed after immunolabeling. Neurite length was

538 quantified for each scaffold type (Fig. 6B). Larger neurite lengths were measured on SF/GO

539 scaffolds compared to unmodified silk, but these differences were not significant. Further

540 analysis revealed maximum neurite extensions of 207, 181, 212, 207, 192, 164, 258 and 151

$541 \mu \mathrm{m}$ for coverslip, SF, SF/1G, SF/5G, SF/10G, SF/1R, SF/5R and SF/10R, respectively. This

542 suggests generation of longer neurites for GO containing scaffolds in comparison to

543 unmodified silk, and tended to reduce for the rGO counterparts. The largest measurement was

544 reported for electroactive SF/5R, though. The average number of neurites expressed per

545 NG108-15 neuronal cell body was estimated at $~ 1.4$ (Fig. 6C), in line with what has been

546 previously reported using the same NG108-15 cell line on other scaffolds [94,95]. The average

547 number of neurites per neuronal cell body decreased at increased GO content, while no

548 differences were observed among the rGO/silk composites. 
A
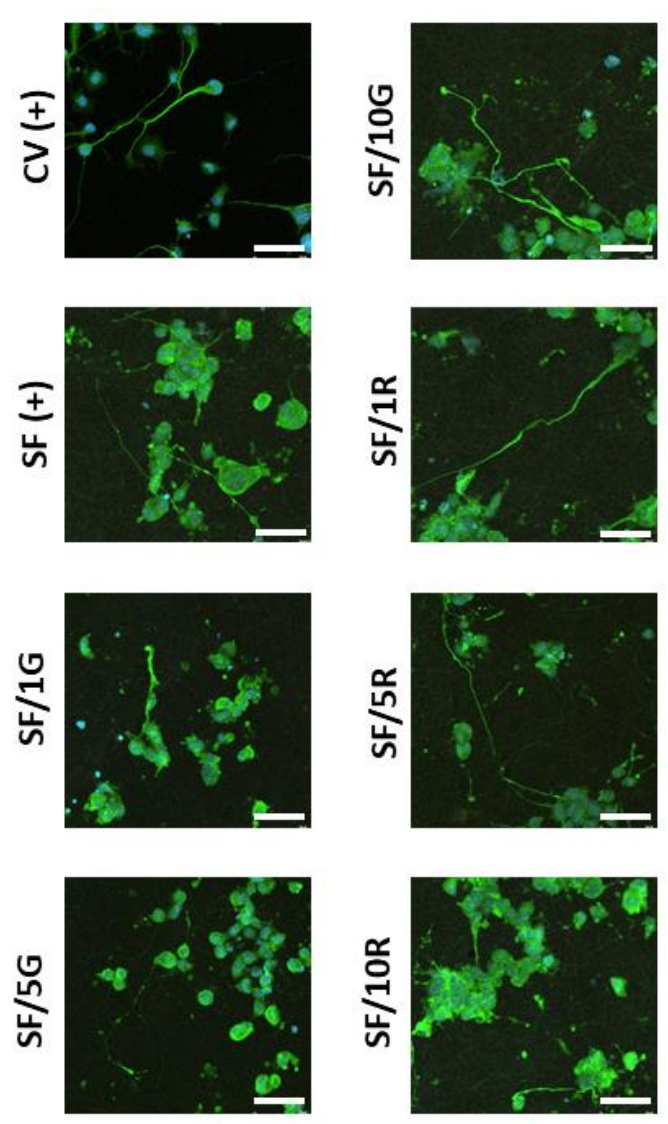

B

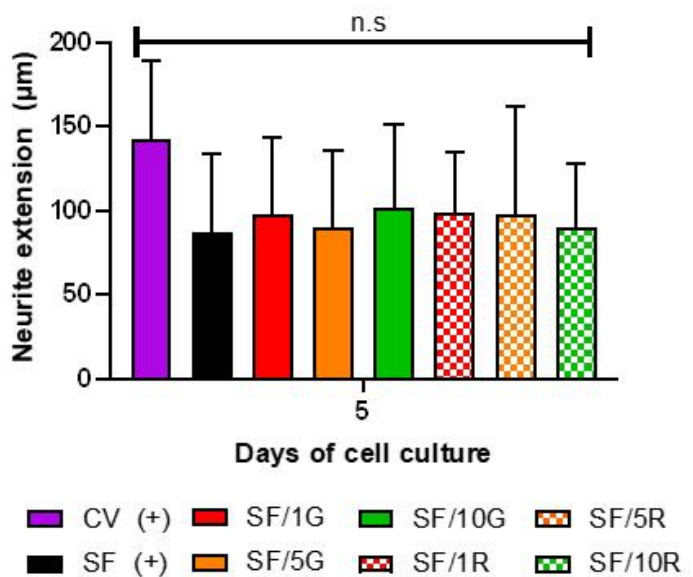

C

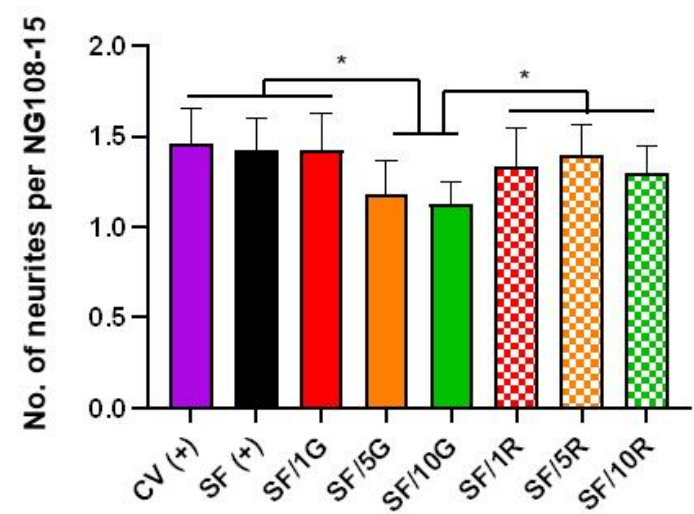

550 Fig. 6 Differentiated NG1081-15 cells on the scaffolds after 5 days of culture: glass coverslip

551 (CV), silk fibroin (SF), 1\% GO/SF (SF/1G), 5\% GO/SF (SF/5G), 10\% GO/SF (SF/10G), $1 \%$

$552 \mathrm{rGO} / \mathrm{SF}(\mathrm{SF} / 1 \mathrm{R}), 5 \% \mathrm{rGO} / \mathrm{SF}(\mathrm{SF} / 5 \mathrm{R})$ and $10 \% \mathrm{rGO} / \mathrm{SF}$ (SF/10R). (A) Representative

553 confocal micrographs of differentiated cells immunolabeled with $\beta$-tubulin III (green) and cell

554 nuclei counterstained with DAPI (blue); scale bar at $75 \mu \mathrm{m}$. (B) Semi-quantitative analysis of

555 the average neurite extension on each scaffold ( $\mathrm{n}=2$ per type). (C) Semi-quantitative analysis

556 of the average number of neurites per neuronal cell body for each scaffold ( $\mathrm{n}=2$ per type).

557 Differences between the experimental groups were analyzed with one-way ANOVA with

$558 \quad$ Tukey's test. n.s non-significant, ${ }^{*} \mathrm{p}<0.05$.

559 Future studies should investigate the degradation properties of the produced scaffolds. Silk

560 fibroin is not expected to degrade within the 7-day culture period in DMEM medium 
undertaken in this study since it has extensive beta-sheet formation. Minimal solubilization and degradation behavior of regenerated silk fibroin has previously been reported in vitro up to 12 weeks [96] in DMEM/PBS conditions. Degradation in vivo could be tailored upon the molecular weight of the regenerated silk fibroin (dissolution method), beta-sheet crystal content [97] and porosity of the scaffold [98,99] to match the degradation rate required for peripheral nerve repair.

\section{4. Conclusion}

568 Delineating the role of electrical conductivity in cell behavior is challenging, since it is difficult

569 to manufacture scaffolds with similar physico-mechanical properties but different levels of conductivity, completely decoupling combined effects. Here, SF composite fibrous scaffolds were manufactured by incorporating GO at loading concentrations up to $10 \%$ wt., optionally followed by in situ post-reduction into electroactive SF/rGO. Presence of GO or rGO did not substantially influence the substrates in terms of the fiber size distribution, porosity, water sorption or protein secondary structure in silk. In contrast, surface roughness and protein adsorption capacity tended to increase with increasing filler content. Reduction treatment into SF/rGO greatly enhanced the electrical conductivity of the scaffolds, which was further promoted after hydration. Analog neuronal NG108-15 cells were able to adhere and survive on all samples. Metabolic activity and proliferation rates were enhanced with the presence of GO and were notably outperformed after reduction into electroactive SF/rGO. Furthermore, these

580 conductive composites supported neurite outgrowth. While it is difficult to pinpoint the parameter responsible for the differing cell responses observed between the GO and rGO counterparts, the inherent electrical regimes conferred by rGO are an important trait over differences in surface roughness or protein adsorption, and further investigation should be warranted. Future studies can look at screening these substrates with other neuronal and 
Schwann cells, or in co-culture conditions. In addition, promotion of neurite outgrowth could be further investigated in combination with aligned fibrous substrates and direct electrical stimulation.

\section{Acknowledgments}

589

AM acknowledges financial support from The University of Manchester EPSRC DTP (grant no. EP/N509565/1, 1786315) in the United Kingdom, and the Agency for Science Technology and Research $\left(A^{*}\right.$ STAR) in Singapore via the A*STAR Research Attachment Programme. The authors also acknowledge the Henry Royce Institute (grant no. EP/R00661X/1, EP/S019367/1, EP/P025021/1 and EP/P025498/1) for support and equipment use. We thank Jorge Magaz

Molina for support in the design of the graphical abstract.

\section{Competing interests}

The authors declare that they have no known competing financial interests or personal relationships that could have appeared to influence the work reported in this study.

\section{References}

599

600

601

602

603

604

605

606

607

608

609

610

611

612

613

614

615

616

617

[1] K. Haastert-Talini, C. Grothe, Electrical stimulation for promoting peripheral nerve regeneration, Int. Rev. Neurobiol. 109 (2013) 111-124. https://doi.org/10.1016/B978-012-420045-6.00005-5.

[2] T. Gordon, A.W. English, Strategies to promote peripheral nerve regeneration: electrical stimulation and/or exercise, Eur. J. Neurosci. 43 (2016) 336-350. https://doi.org/10.1111/ejn.13005.

[3] T. Gordon, O.A.R. Sulaiman, A. Ladak, Chapter 24: Electrical stimulation for improving nerve regeneration: where do we stand?, Int. Rev. Neurobiol. 87 (2009) 433444. https://doi.org/10.1016/S0074-7742(09)87024-4.

[4] H. Palza, P.A. Zapata, C. Angulo-Pineda, Electroactive smart polymers for biomedical applications, Materials. 12 (2019) 277. https://doi.org/10.3390/ma12020277.

[5] N. Amdursky, X. Wang, P. Meredith, D.D.C. Bradley, M.M. Stevens, Long-range proton conduction across free-standing serum albumin mats, Adv Mater. 28 (2016) 2692-2698. https://doi.org/10.1002/adma.201505337.

[6] A. Burnstine-Townley, Y. Eshel, N. Amdursky, Conductive scaffolds for cardiac and neuronal tissue engineering: governing factors and mechanisms, Adv. Funct. Mater. 30 (2020) 1901369. https://doi.org/10.1002/adfm.201901369.

[7] K. Hatakeyama, K. Awaya, M. Koinuma, Y. Shimizu, Y. Hakuta, Y. Matsumoto, Production of water-dispersible reduced graphene oxide without stabilizers using liquid- 
phase photoreduction, Soft Matter. 13 (2017) 8353-8356. https://doi.org/10.1039/C7SM01386H.

[8] G. Kaur, R. Adhikari, P. Cass, M. Bown, P. Gunatillake, Electrically conductive polymers and composites for biomedical applications, RSC Adv. 5 (2015) 3755337567. https://doi.org/10.1039/C5RA01851J.

[9] S. Song, P.M. George, Conductive polymer scaffolds to improve neural recovery, Neural Regen Res. 12 (2017) 1976-1978. https://doi.org/10.4103/1673-5374.221151.

[10] R. Balint, N.J. Cassidy, S.H. Cartmell, Conductive polymers: Towards a smart biomaterial for tissue engineering, Acta Biomater. 10 (2014) 2341-2353. https://doi.org/10.1016/j.actbio.2014.02.015.

[11] E.M. Thaning, M.L.M. Asplund, T.A. Nyberg, O.W. Inganäs, H. von Holst, Stability of poly(3,4-ethylene dioxythiophene) materials intended for implants, J. Biomed. Mater. Res., Part B. 93B (2010) 407-415. https://doi.org/10.1002/jbm.b.31597.

[12] A. Magaz, A. Faroni, J.E. Gough, A.J. Reid, X. Li, J.J. Blaker, Bioactive silk-based nerve guidance conduits for augmenting peripheral nerve repair, Adv. Healthc. Mater. 7 (2018) 1800308. https://doi.org/10.1002/adhm.201800308.

[13] A.H. Castro Neto, F. Guinea, N.M.R. Peres, K.S. Novoselov, A.K. Geim, The electronic properties of graphene, Rev. Mod. Phys. 81 (2009) 109-162. https://doi.org/10.1103/RevModPhys.81.109.

[14] C. Lee, X. Wei, J.W. Kysar, J. Hone, Measurement of the elastic properties and intrinsic strength of monolayer graphene, Science. 321 (2008) 385-388. https://doi.org/10.1126/science.1157996.

[15] M.D. Stoller, S. Park, Y. Zhu, J. An, R.S. Ruoff, Graphene-based ultracapacitors, Nano Lett. 8 (2008) 3498-3502. https://doi.org/10.1021/n1802558y.

[16] J. Lee, J. Kim, S. Kim, D.-H. Min, Biosensors based on graphene oxide and its biomedical application, Adv. Drug Deliv. Rev. 105 (2016) 275-287. https://doi.org/10.1016/j.addr.2016.06.001.

[17] D.P. Singh, C.E. Herrera, B. Singh, S. Singh, R.K. Singh, R. Kumar, Graphene oxide: An efficient material and recent approach for biotechnological and biomedical applications, Mater Sci Eng C. 86 (2018) 173-197. https://doi.org/10.1016/j.msec.2018.01.004.

[18] M. Lv, Y. Zhang, L. Liang, M. Wei, W. Hu, X. Li, Q. Huang, Effect of graphene oxide on undifferentiated and retinoic acid-differentiated SH-SY5Y cells line, Nanoscale. 4 (2012) 3861-3866. https://doi.org/10.1039/C2NR30407D.

[19] N. Tasnim, A. Kumar, B. Joddar, Attenuation of the in vitro neurotoxicity of 316L SS by graphene oxide surface coating, Mater. Sci. Eng. C. 73 (2017) 788-797. https://doi.org/10.1016/j.msec.2016.12.123.

[20] H.-G. Oh, H.-G. Nam, D.-H. Kim, M.-H. Kim, K.-H. Jhee, K.S. Song, Neuroblastoma cells grown on fluorine or oxygen treated graphene sheets, Mater. Lett. 131 (2014) 328 331. https://doi.org/10.1016/j.matlet.2014.06.013.

[21] M.C. Serrano, J. Patiño, C. García-Rama, M.L. Ferrer, J.L.G. Fierro, A. Tamayo, J.E. Collazos-Castro, F. del Monte, M.C. Gutiérrez, 3D free-standing porous scaffolds made of graphene oxide as substrates for neural cell growth, J. Mater. Chem. B. 2 (2014) 5698-5706. https://doi.org/10.1039/C4TB00652F.

[22] J. Wang, W. Zheng, L. Chen, T. Zhu, W. Shen, C. Fan, H. Wang, X. Mo, Enhancement of schwann cells function using graphene-oxide-modified nanofiber scaffolds for peripheral nerve regeneration, ACS Biomater. Sci. Eng. 5 (2019) 2444-2456. https://doi.org/10.1021/acsbiomaterials.8b01564. 
681

682

683

684

685

686

687

688

689

690

691

692

693

694

695

696

697

698

699

700

701

702

703

704

705

706

707

708

709

710

711

712

[23] K. Yang, J. Lee, J.S. Lee, D. Kim, G.-E. Chang, J. Seo, E. Cheong, T. Lee, S.-W. Cho, Graphene oxide hierarchical patterns for the derivation of electrophysiologically functional neuron-like cells from human neural stem cells, ACS Appl Mater Interfaces. 8 (2016) 17763-17774. https://doi.org/10.1021/acsami.6b01804.

[24] D. Yang, T. Li, M. Xu, F. Gao, J. Yang, Z. Yang, W. Le, Graphene oxide promotes the differentiation of mouse embryonic stem cells to dopamine neurons, Nanomedicine. 9 (2014) 2445-2455. https://doi.org/10.2217/nnm.13.197.

[25] A. Portone, M. Moffa, C. Gardin, L. Ferroni, M. Tatullo, F. Fabbri, L. Persano, A. Piattelli, B. Zavan, D. Pisignano, Lineage-specific commitment of stem cells with organic and graphene oxide-functionalized nanofibers, Adv. Funct. Mater. 29 (2019) 1806694. https://doi.org/10.1002/adfm.201806694.

[26] Q. Ma, L. Yang, Z. Jiang, Q. Song, M. Xiao, D. Zhang, X. Ma, T. Wen, G. Cheng, Three-dimensional stiff graphene scaffold on neural stem cells behavior, ACS Appl. Mater. Interfaces. 8 (2016) 34227-34233. https://doi.org/10.1021/acsami.6b12305.

[27] W. Guo, S. Wang, X. Yu, J. Qiu, J. Li, W. Tang, Z. Li, X. Mou, H. Liu, Z. Wang, Construction of a 3D rGO-collagen hybrid scaffold for enhancement of the neural differentiation of mesenchymal stem cells, Nanoscale. 8 (2016) 1897-1904. https://doi.org/10.1039/C5NR06602F.

[28] J.S. Lee, A. Lipatov, L. Ha, M. Shekhirev, M.N. Andalib, A. Sinitskii, J.Y. Lim, Graphene substrate for inducing neurite outgrowth, Biochem. Biophys. Res. Commun. 460 (2015) 267-273. https://doi.org/10.1016/j.bbrc.2015.03.023.

[29] S.W. Hong, J.H. Lee, S.H. Kang, E.Y. Hwang, Y.-S. Hwang, M.H. Lee, D.-W. Han, J.C. Park, Enhanced neural cell adhesion and neurite outgrowth on graphene-based biomimetic substrates, Biomed Res Int. 2014 (2014) 212149. https://doi.org/10.1155/2014/212149.

[30] Q. Tu, L. Pang, L. Wang, Y. Zhang, R. Zhang, J. Wang, Biomimetic choline-like graphene oxide composites for neurite sprouting and outgrowth, ACS Appl. Mater. Interfaces. 5 (2013) 13188-13197. https://doi.org/10.1021/am4042004.

[31] O. Akhavan, E. Ghaderi, The use of graphene in the self-organized differentiation of human neural stem cells into neurons under pulsed laser stimulation, J. Mater. Chem. B. 2 (2014) 5602-5611. https://doi.org/10.1039/C4TB00668B.

[32] J. Wang, Y. Cheng, L. Chen, T. Zhu, K. Ye, C. Jia, H. Wang, M. Zhu, C. Fan, X. Mo, In vitro and in vivo studies of electroactive reduced graphene oxide-modified nanofiber scaffolds for peripheral nerve regeneration, Acta Biomater. 84 (2019) 98-113. https://doi.org/10.1016/j.actbio.2018.11.032.

[33] R. Guo, S. Zhang, M. Xiao, F. Qian, Z. He, D. Li, X. Zhang, H. Li, X. Yang, M. Wang, R. Chai, M. Tang, Accelerating bioelectric functional development of neural stem cells by graphene coupling: Implications for neural interfacing with conductive materials, Biomaterials. 106 (2016) 193-204. https://doi.org/10.1016/j.biomaterials.2016.08.019.

[34] A. Alessandrino, F. Fregnan, M. Biagiotti, L. Muratori, G.A. Bassani, G. Ronchi, V. Vincoli, P. Pierimarchi, S. Geuna, G. Freddi, SilkBridge ${ }^{\mathrm{TM}}$ : a novel biomimetic and biocompatible silk-based nerve conduit, Biomater. Sci. 7 (2019) 4112-4130. https://doi.org/10.1039/C9BM00783K.

[35] M. Gholipourmalekabadi, A. Samadikuchaksaraei, A.M. Seifalian, A.M. Urbanska, H. Ghanbarian, J.G. Hardy, M.D. Omrani, M. Mozafari, R.L. Reis, S.C. Kundu, Silk fibroin/amniotic membrane 3D bi-layered artificial skin, Biomed. Mater. 13 (2018) 035003. https://doi.org/10.1088/1748-605X/aa999b. 
[36] C. Zhang, S. Fan, H. Shao, X. Hu, B. Zhu, Y. Zhang, Graphene trapped silk scaffolds integrate high conductivity and stability, Carbon. 148 (2019) 16-27. https://doi.org/10.1016/j.carbon.2019.03.042.

[37] L. Zulan, L. Zhi, C. Lan, C. Sihao, W. Dayang, D. Fangyin, Reduced graphene oxide coated silk fabrics with conductive property for wearable electronic textiles application, Adv. Electron. Mater. 5 (2019) 1800648. https://doi.org/10.1002/aelm.201800648.

[38] G. Zhao, H. Qing, G. Huang, G.M. Genin, T.J. Lu, Z. Luo, F. Xu, X. Zhang, Reduced graphene oxide functionalized nanofibrous silk fibroin matrices for engineering excitable tissues, NPG Asia Mater. 10 (2018) 982. https://doi.org/10.1038/s41427-0180092-8.

[39] J. Cao, C. Wang, Multifunctional surface modification of silk fabric via graphene oxide repeatedly coating and chemical reduction method, Applied Surface Science. 405 (2017) 380-388. https://doi.org/10.1016/j.apsusc.2017.02.017.

[40] H. Qing, G. Jin, G. Zhao, G. Huang, Y. Ma, X. Zhang, B. Sha, Z. Luo, T.J. Lu, F. Xu, Heterostructured silk-nanofiber-reduced graphene oxide composite scaffold for $\mathrm{SH}$ SY5Y cell alignment and differentiation, ACS Appl. Mater. Interfaces. 10 (2018) 39228-39237. https://doi.org/10.1021/acsami.8b12562.

[41] A. Magaz, A.D. Roberts, S. Faraji, T.R.L. Nascimento, E.S. Medeiros, W. Zhang, R.D. Greenhalgh, A. Mautner, X. Li, J.J. Blaker, Porous, aligned, and biomimetic fibers of regenerated silk fibroin produced by solution blow spinning, Biomacromolecules. 19 (2018) 4542-4553. https://doi.org/10.1021/acs.biomac.8b01233.

[42] S. Aznar-Cervantes, A. Pagán, J.G. Martínez, A. Bernabeu-Esclapez, T.F. Otero, L. Meseguer-Olmo, J.I. Paredes, J.L. Cenis, Electrospun silk fibroin scaffolds coated with reduced graphene promote neurite outgrowth of PC-12 cells under electrical stimulation, Mater. Sci. Eng. C. 79 (2017) 315-325. https://doi.org/10.1016/j.msec.2017.05.055.

[43] S.J. Eichhorn, W.W. Sampson, Relationships between specific surface area and pore size in electrospun polymer fibre networks, J R Soc Interface. 7 (2010) 641-649. https://doi.org/10.1098/rsif.2009.0374.

[44] D. Kai, M.P. Prabhakaran, G. Jin, S. Ramakrishna, Biocompatibility evaluation of electrically conductive nanofibrous scaffolds for cardiac tissue engineering, J. Mater. Chem. B. 1 (2013) 2305-2314. https://doi.org/10.1039/C3TB00151B.

[45] S. Wang, C. Sun, S. Guan, W. Li, J. Xu, D. Ge, M. Zhuang, T. Liu, X. Ma, Chitosan/gelatin porous scaffolds assembled with conductive poly(3,4ethylenedioxythiophene) nanoparticles for neural tissue engineering, J. Mater. Chem. B. 5 (2017) 4774-4788. https://doi.org/10.1039/C7TB00608J.

[46] B. Tandon, P. Kamble, R.T. Olsson, J.J. Blaker, S.H. Cartmell, Fabrication and characterisation of stimuli responsive piezoelectric PVDF and hydroxyapatite-filled pvdf fibrous membranes, Molecules. 24 (2019) 1903. https://doi.org/10.3390/molecules24101903.

[47] J. Serth, M.A. Kuczyk, U. Paeslack, R. Lichtinghagen, U. Jonas, Quantitation of DNA extracted after micropreparation of cells from frozen and formalin-fixed tissue sections, Am. J. Pathol. 156 (2000) 1189-1196. https://doi.org/10.1016/S0002-9440(10)64989-9.

[48] G. Cheng, X. Wang, S. Tao, J. Xia, S. Xu, Differences in regenerated silk fibroin prepared with different solvent systems: From structures to conformational changes, J. Appl. Polym. Sci. 132 (2015) 41959. https://doi.org/10.1002/app.41959.

[49] S. Ye, J. Feng, The effect of sonication treatment of graphene oxide on the mechanical properties of the assembled films, RSC Adv. 6 (2016) 39681-39687. https://doi.org/10.1039/C6RA03996K. 
[50] X. Qi, T. Zhou, S. Deng, G. Zong, X. Yao, Q. Fu, Size-specified graphene oxide sheets: ultrasonication assisted preparation and characterization, J Mater Sci. 49 (2014) 17851793. https://doi.org/10.1007/s10853-013-7866-8.

[51] C. Cai, N. Sang, Z. Shen, X. Zhao, Facile and size-controllable preparation of graphene oxide nanosheets using high shear method and ultrasonic method, J. Exp. Nanosci. 12 (2017) 247-262. https://doi.org/10.1080/17458080.2017.1303853.

[52] T. Zhou, G. Li, S. Lin, T. Tian, Q. Ma, Q. Zhang, S. Shi, C. Xue, W. Ma, X. Cai, Y. Lin, Electrospun poly(3-hydroxybutyrate-co-4-hydroxybutyrate)/graphene oxide scaffold: enhanced properties and promoted in vivo bone repair in rats, ACS Appl. Mater. Interfaces. 9 (2017) 42589-42600. https://doi.org/10.1021/acsami.7b14267.

[53] C. Wang, Y. Li, G. Ding, X. Xie, M. Jiang, Preparation and characterization of graphene oxide/poly(vinyl alcohol) composite nanofibers via electrospinning, J. Appl. Polym. Sci. 127 (2013) 3026-3032. https://doi.org/10.1002/app.37656.

[54] T. Huang, B. Zheng, L. Kou, K. Gopalsamy, Z. Xu, C. Gao, Y. Meng, Z. Wei, Flexible high performance wet-spun graphene fiber supercapacitors, RSC Adv. 3 (2013) 2395723962. https://doi.org/10.1039/C3RA44935A.

[55] M. Ezra, J. Bushman, D. Shreiber, M. Schachner, J. Kohn, Porous and nonporous nerve conduits: the effects of a hydrogel luminal filler with and without a neurite-promoting moiety, Tissue Eng Part A. 22 (2016) 818-826. https://doi.org/10.1089/ten.tea.2015.0354.

[56] K. Roshanbinfar, Z. Mohammadi, A.S.-M. Mesgar, M.M. Dehghan, O.P. Oommen, J. Hilborn, F.B. Engel, Carbon nanotube doped pericardial matrix derived electroconductive biohybrid hydrogel for cardiac tissue engineering, Biomater. Sci. 7 (2019) 3906-3917. https://doi.org/10.1039/C9BM00434C.

[57] Y. Zhao, J. Gong, C. Niu, Z. Wei, J. Shi, G. Li, Y. Yang, H. Wang, A new electrospun graphene-silk fibroin composite scaffolds for guiding Schwann cells, J. Biomater. Sci. Polym. Ed. 28 (2017) 2171-2185. https://doi.org/10.1080/09205063.2017.1386835.

[58] J. Tao, Y. Hu, S. Wang, J. Zhang, X. Liu, Z. Gou, H. Cheng, Q. Liu, Q. Zhang, S. You, M. Gou, A 3D-engineered porous conduit for peripheral nerve repair, Sci. Rep. 7 (2017) 46038. https://doi.org/10.1038/srep46038.

[59] J. Kucinska-Lipka, M. Marzec, I. Gubanska, H. Janik, Porosity and swelling properties of novel polyurethane-ascorbic acid scaffolds prepared by different procedures for potential use in bone tissue engineering, J Elastom Plast. 49 (2017) 440-456. https://doi.org/10.1177/0095244316672093.

[60] Y. Cheng, L.-D. Koh, D. Li, B. Ji, M.-Y. Han, Y.-W. Zhang, On the strength of $\beta$-sheet crystallites of Bombyx mori silk fibroin, J R Soc Interface. 11 (2014) 20140305. https://doi.org/10.1098/rsif.2014.0305.

[61] W. Wang, G. Caetano, W.S. Ambler, J.J. Blaker, M.A. Frade, P. Mandal, C. Diver, P. Bártolo, Enhancing the hydrophilicity and cell attachment of 3D printed PCL/graphene scaffolds for bone tissue engineering, Materials. 9 (2016) 992. https://doi.org/10.3390/ma9120992.

[62] L.A. Belyaeva, P.M.G. van Deursen, K.I. Barbetsea, G.F. Schneider, Hydrophilicity of graphene in water through transparency to polar and dispersive interactions, Adv Mater. 30 (2018) 1703274. https://doi.org/10.1002/adma.201703274.

[63] R. Balu, S. Reeder, R. Knott, J. Mata, L. de Campo, N.K. Dutta, N.R. Choudhury, Tough photocrosslinked silk fibroin/graphene oxide nanocomposite hydrogels, Langmuir. 34 (2018) 9238-9251. https://doi.org/10.1021/acs.langmuir.8b01141. 
[64] C. Zhang, Y. Zhang, H. Shao, X. Hu, Hybrid silk fibers dry-spun from regenerated silk fibroin/graphene oxide aqueous solutions, ACS Appl. Mater. Interfaces. 8 (2016) 33493358. https://doi.org/10.1021/acsami.5b11245.

[65] N. Izyan Syazana Mohd Yusoff, M. Uzir Wahit, J. Jaafar, T.-W. Wong, Characterization of graphene-silk fibroin composites film, Mater. Today. 5 (2018) 21853-21860. https://doi.org/10.1016/j.matpr.2018.07.042.

[66] X. Chen, Z. Shao, N.S. Marinkovic, L.M. Miller, P. Zhou, M.R. Chance, Conformation transition kinetics of regenerated Bombyx mori silk fibroin membrane monitored by time-resolved FTIR spectroscopy, Biophys. Chem. 89 (2001) 25-34. https://doi.org/10.1016/S0301-4622(00)00213-1.

[67] X. Chen, D.P. Knight, Z. Shao, $\beta$-turn formation during the conformation transition in silk fibroin, Soft Matter. 5 (2009) 2777-2781. https://doi.org/10.1039/B900908F.

[68] K. Li, P. Li, Y. Fan, The assembly of silk fibroin and graphene-based nanomaterials with enhanced mechanical/conductive properties and their biomedical applications, Journal of Materials Chemistry B. 7 (2019) 6890-6913. https://doi.org/10.1039/C9TB01733J.

[69] S. Coh, L.Z. Tan, S.G. Louie, M.L. Cohen, Theory of the Raman spectrum of rotated double-layer graphene, Phys. Rev. B. 88 (2013) 165431. https://doi.org/10.1103/PhysRevB.88.165431.

[70] C. Angulo-Pineda, K. Srirussamee, P. Palma, V.M. Fuenzalida, S.H. Cartmell, H. Palza, Electroactive 3D printed scaffolds based on percolated composites of polycaprolactone with thermally reduced graphene oxide for antibacterial and tissue engineering applications, Nanomaterials. 10 (2020) 428. https://doi.org/10.3390/nano10030428.

[71] H. Aguilar-Bolados, M.A. Lopez-Manchado, J. Brasero, F. Avilés, M. Yazdani-Pedram, Effect of the morphology of thermally reduced graphite oxide on the mechanical and electrical properties of natural rubber nanocomposites, Compos Part B-Eng. 87 (2016) 350-356. https://doi.org/10.1016/j.compositesb.2015.08.079.

[72] S. Wang, L. Shi, S. Zhang, H. Wang, B. Cheng, X. Zhuang, Z. Li, Proton-conducting amino acid-modified chitosan nanofibers for nanocomposite proton exchange membranes, Eur. Polym. J. 119 (2019) 327-334. https://doi.org/10.1016/j.eurpolymj.2019.07.041.

[73] K. Roshanbinfar, L. Vogt, B. Greber, S. Diecke, A.R. Boccaccini, T. Scheibel, F.B. Engel, Electroconductive biohybrid hydrogel for enhanced maturation and beating properties of engineered cardiac tissues, Adv. Funct. Mater. 28 (2018) 1803951. https://doi.org/10.1002/adfm.201803951.

[74] N. Annabi, S.R. Shin, A. Tamayol, M. Miscuglio, M.A. Bakooshli, A. Assmann, P. Mostafalu, J.-Y. Sun, S. Mithieux, L. Cheung, X.S. Tang, A.S. Weiss, A. Khademhosseini, Highly elastic and conductive human-based protein hybrid hydrogels, Adv. Mater. Weinheim. 28 (2016) 40-49. https://doi.org/10.1002/adma.201503255.

[75] A.M. Martins, G. Eng, S.G. Caridade, J.F. Mano, R.L. Reis, G. Vunjak-Novakovic, Electrically conductive chitosan/carbon scaffolds for cardiac tissue engineering, Biomacromolecules. 15 (2014) 635-643. https://doi.org/10.1021/bm401679q.

[76] C. Zhong, Y. Deng, A.F. Roudsari, A. Kapetanovic, M.P. Anantram, M. Rolandi, A polysaccharide bioprotonic field-effect transistor, Nat Commun. 2 (2011) 476. https://doi.org/10.1038/ncomms1489.

[77] D.D. Ordinario, L. Phan, W.G. Walkup, J.-M. Jocson, E. Karshalev, N. Hüsken, A.A. Gorodetsky, Bulk protonic conductivity in a cephalopod structural protein, Nat Chem. 6 (2014) 596-602. https://doi.org/10.1038/nchem.1960. 
[78] Y. Deng, E. Josberger, J. Jin, A.F. Roudsari, A.F. Rousdari, B.A. Helms, C. Zhong, M.P. Anantram, M. Rolandi, H+-type and $\mathrm{OH}$ - -type biological protonic semiconductors and complementary devices, Sci Rep. 3 (2013) 2481. https://doi.org/10.1038/srep02481.

[79] A. Pena-Francesch, H. Jung, M.A. Hickner, M. Tyagi, B.D. Allen, M.C. Demirel, Programmable proton conduction in stretchable and self-healing proteins, Chem. Mater. 30 (2018) 898-905. https://doi.org/10.1021/acs.chemmater.7b04574.

[80] B. Tulachan, S.K. Meena, R.K. Rai, C. Mallick, T.S. Kusurkar, A.K. Teotia, N.K. Sethy, K. Bhargava, S. Bhattacharya, A. Kumar, R.K. Sharma, N. Sinha, S.K. Singh, M. Das, Electricity from the silk cocoon membrane, Sci Rep. 4 (2014) 5434.

[81] C. Gabriel, S. Gabriel, E. Corthout, The dielectric properties of biological tissues: I. Literature survey, Phys. Med. Biol. 41 (1996) 2231-2249. https://doi.org/10.1088/00319155/41/11/001.

[82] Y. Wu, L. Wang, B. Guo, Y. Shao, P.X. Ma, Electroactive biodegradable polyurethane significantly enhanced Schwann cells myelin gene expression and neurotrophin secretion for peripheral nerve tissue engineering, Biomaterials. 87 (2016) 18-31. https://doi.org/10.1016/j.biomaterials.2016.02.010.

[83] J.C. Niple, J.P. Daigle, L.E. Zaffanella, T. Sullivan, R. Kavet, A portable meter for measuring low frequency currents in the human body, Bioelectromagnetics. 25 (2004) 369-373. https://doi.org/10.1002/bem.20000.

[84] A.J. Ryan, C.J. Kearney, N. Shen, U. Khan, A.G. Kelly, C. Probst, E. Brauchle, S. Biccai, C.D. Garciarena, V. Vega-Mayoral, P. Loskill, S.W. Kerrigan, D.J. Kelly, K. Schenke-Layland, J.N. Coleman, F.J. O’Brien, Electroconductive biohybrid collagen/pristine graphene composite biomaterials with enhanced biological activity, Adv. Mater. 30 (2018) 1706442. https://doi.org/10.1002/adma.201706442.

[85] L. Ou, B. Song, H. Liang, J. Liu, X. Feng, B. Deng, T. Sun, L. Shao, Toxicity of graphene-family nanoparticles: a general review of the origins and mechanisms, Part Fibre Toxicol. 13 (2016) 57. https://doi.org/10.1186/s12989-016-0168-y.

[86] A. Magaz, M.D. Ashton, R.M. Hathout, X. Li, J.G. Hardy, J.J. Blaker, Electroresponsive silk-based biohybrid composites for electrochemically controlled growth factor delivery, Pharmaceutics. 12 (2020) 742. https://doi.org/10.3390/pharmaceutics12080742.

[87] F. Zamani, M. Amani-Tehran, M. Latifi, M.A. Shokrgozar, The influence of surface nanoroughness of electrospun PLGA nanofibrous scaffold on nerve cell adhesion and proliferation, J Mater Sci: Mater Med. 24 (2013) 1551-1560. https://doi.org/10.1007/s10856-013-4905-6.

[88] D.A. Stout, J. Yoo, A.N. Santiago-Miranda, T.J. Webster, Mechanisms of greater cardiomyocyte functions on conductive nanoengineered composites for cardiovascular application, Int J Nanomedicine. 7 (2012) 5653-5669. https://doi.org/10.2147/IJN.S34574.

[89] Z. Zhou, X. Liu, W. Wu, S. Park, A.L.M. Ii, A. Terzic, L. Lu, Effective nerve cell modulation by electrical stimulation of carbon nanotube embedded conductive polymeric scaffolds, Biomater. Sci. 6 (2018) 2375-2385. https://doi.org/10.1039/C8BM00553B.

[90] T. Akkas, C. Citak, A. Sirkecioglu, F.S. Güner, Which is more effective for protein adsorption: surface roughness, surface wettability or swelling? Case study of polyurethane films prepared from castor oil and poly(ethylene glycol), Polym. Int. 62 (2013) 1202-1209. https://doi.org/10.1002/pi.4408. 
[91] Y. Chong, C. Ge, Z. Yang, J.A. Garate, Z. Gu, J.K. Weber, J. Liu, R. Zhou, Reduced Cytotoxicity of Graphene Nanosheets Mediated by Blood-Protein Coating, ACS Nano. 9 (2015) 5713-5724. https://doi.org/10.1021/nn5066606.

[92] S. Kumar, S.H. Parekh, Linking graphene-based material physicochemical properties with molecular adsorption, structure and cell fate, Commun. Chem. 3 (2020) 1-11. https://doi.org/10.1038/s42004-019-0254-9.

[93] X. Shi, H. Chang, S. Chen, C. Lai, A. Khademhosseini, H. Wu, Regulating cellular behavior on few-layer reduced graphene oxide films with well-controlled reduction states, Adv Funct Mater. 22 (2012) 751-759. https://doi.org/10.1002/adfm.201102305.

[94] R. Diez-Ahedo, X. Mendibil, M.C. Márquez-Posadas, I. Quintana, F. González, F.J. Rodríguez, L. Zilic, C. Sherborne, A. Glen, C.S. Taylor, F. Claeyssens, J.W. Haycock, W. Schaafsma, E. González, B. Castro, S. Merino, UV-casting on methacrylated PCL for the production of a peripheral nerve implant containing an array of porous aligned microchannels, Polymers. 12 (2020) 971. https://doi.org/10.3390/polym12040971.

[95] M.F.B. Daud, K.C. Pawar, F. Claeyssens, A.J. Ryan, J.W. Haycock, An aligned 3D neuronal-glial co-culture model for peripheral nerve studies, Biomaterials. 33 (2012) 5901-5913. https://doi.org/10.1016/j.biomaterials.2012.05.008.

[96] M. Farokhi, F. Mottaghitalab, J. Hadjati, R. Omidvar, M. Majidi, A. Amanzadeh, M. Azami, S.M. Tavangar, M.A. Shokrgozar, J. Ai, Structural and functional changes of silk fibroin scaffold due to hydrolytic degradation, Journal of Applied Polymer Science. 131 (2014). https://doi.org/10.1002/app.39980.

[97] Q. Lu, B. Zhang, M. Li, B. Zuo, D.L. Kaplan, Y. Huang, H. Zhu, Degradation mechanism and control of silk fibroin, Biomacromolecules. 12 (2011) 1080-1086. https://doi.org/10.1021/bm101422j.

[98] Y. Wang, D.D. Rudym, A. Walsh, L. Abrahamsen, H.-J. Kim, H.S. Kim, C. KirkerHead, D.L. Kaplan, In vivo degradation of three-dimensional silk fibroin scaffolds, Biomaterials. 29 (2008) 3415-3428. https://doi.org/10.1016/j.biomaterials.2008.05.002.

[99] L. Zhang, X. Liu, G. Li, P. Wang, Y. Yang, Tailoring degradation rates of silk fibroin scaffolds for tissue engineering, Journal of Biomedical Materials Research Part A. 107 (2019) 104-113. https://doi.org/10.1002/jbm.a.36537. 